\title{
Die Bedeutung der Kodifikation im Verwaltungsrecht
}

\author{
Wolfgang Kahl/Patrick Hilbert"
}

A. Einleitung ........................ 453

B. Begriff und Typen der Kodifikation ... 454

I. Begriff .......................... 454

II. Typen ......................... 455

1. Generalkodifikation - Bereichs-

kodifikation ................... 455

2. Gesamtkodifikation - Teilkodifikation ........................ 456

III. Allgemeine Teile als Essenz einer

Kodifikation ...................... 456

C. Funktionen der Kodifikation .......... 458

D. Kodifikation als Aufgabe von Gesetzgebung und Wissenschaft........... 459

I. Einwände gegen die Kodifikationsidee ........................... 459

1. Generelle Einwände gegen die Kodifikationsidee............. 459

a) Grundsätzliche Einwände. . . 459

b) Europäisierung als Einwand ................... 460

c) Regelungspraktische Einwände... 462

2. Spezielle Einwände gegen die Kodifikationsidee im Öffentlichen Recht... 463

II. Die Rolle der Gesetzgebung . 464
III. Die Rolle der Wissenschaft . 466

E. Kodifikationen im deutschen Verwaltungsrecht: Bestand und Bestrebungen ............................. 467

I. Allgemeines Verwaltungsrecht...... 468

II. Verwaltungsprozessrecht ........... 469

III. Besonderes Verwaltungsrecht....... 471

F. Das VwVfG als Kodifikation......... 473

I. Allgemeines .................... 473

II. Stärken ........................... 474

III. Schwächen ........................ 475

IV. Simultangesetzgebung ............. 479

V. Reformbestrebungen .............. 480

1. Eröffnungskontrollen und (förmliche) Genehmigungsverfahren ...................... 481

2. Verfahrensfehlerfolgen ........ 482

3. Bürgerbeteiligung bei Großvorhaben ......................... 483

4. Rekodifikation des Planfeststellungsrechts.................. 485

5. Informationszugang .......... 486

6. Verwaltungskooperationsrecht....................... 487

G. Schluss ......................... 488

\section{A. Einleitung}

Die Kodifikationsidee ist ambivalent. ${ }^{1}$ Einerseits wird die Kodifikation als „Ideal der Gesetzgebung“ ausgerufen, ${ }^{2}$ andererseits als im heutigen demokratischen Rechtsstaat nicht mehr mögliches Relikt vergangener Zeiten abgeschrieben. ${ }^{3}$ Eine Annäherung an die Bedeutung der Kodifikation im Verwaltungsrecht, dem anders als dem Zivil- und Strafrecht eine lange Tradition der Kodifikation fehlt, wird sich zwischen diesen Extrempositionen bewegen müssen. Hierfür soll ausgehend von allgemeinen Überlegungen zur Ausdifferenzierung des Kodifikationsbegriffs in modernen Rechts-

* Prof. Dr. Wolfgang Kahl, M.A. ist geschäftsführender Direktor des Instituts für deutsches und europäisches Verwaltungsrecht sowie der Forschungsstelle für Nachhaltigkeitsrecht an der Ruprecht-KarlsUniversität Heidelberg. Patrick Hilbert ist ebendort Wissenschaftlicher Mitarbeiter und Doktorand.

1 A. Voßkuble, Kodifikation als Prozeß, in: H. Schlosser (Hrsg.), Bürgerliches Gesetzbuch 1896 - 1996, Heidelberg 1997, S. 77 (83).

2 R. Breuer, Betrachtungen zur Lage der Gesetzgebung, in: O. Depenheuer/M. Heintzen/M. Jestaedt/P. Axer (Hrsg.), Staat im Wort. Festschrift für Josef Isensee, Heidelberg 2007, S. 345 (345).

3 F. Kübler, Kodifikation und Demokratie, JZ 1969, S. 645 ff.: „Das alles läßt nur den Schluß zu, daß unter den in der Bundesrepublik gegebenen wirtschaftlichen, gesellschaftlichen und politischen Voraussetzungen Kodifikation als ein Instrument rechtlicher Gestaltung und Ordnung nicht mehr verfügbar ist." (S. 648). 
ordnungen (B.), den Funktionen einer Kodifikation (C.) sowie den Schwierigkeiten der Kodifikationsgesetzgebung (D.) der Blick auf die Kodifikationen im deutschen Verwaltungsrecht gelenkt werden (E.). Deren wichtigste, das VwVfG, soll exemplarisch einer näheren Betrachtung unterzogen werden, weil sich an ihm Probleme und Potenz der Kodifikation im Verwaltungsrecht am deutlichsten zeigen (F.). Nicht eingegangen werden kann in diesem Beitrag auf die Kodifikation des Europäischen Verwaltungsrechts, insbesondere des Eigenverwaltungsrechts und des Unionsverwaltungsrechts. ${ }^{4}$

\section{B. Begriff und Typen der Kodifikation}

\section{Begriff}

Nach klassischem Verständnis ist eine Kodifikation die abschließende und lückenlose Regelung eines bestimmten Sachgebiets. ${ }^{5}$ Dieses Ideal war nie erreichbar ${ }^{6}$ und passt nicht in einen auf Demokratie und Pluralität gestützten Rechtsstaat, ${ }^{7}$ weshalb der Anspruch auf Vollständigkeit heute stark zurückgenommen ist. ${ }^{8}$ Gleichwohl ist der Begriff „Kodifikation“ mit Recht nicht aufgegeben worden. Er erfährt seine Berechtigung aus dem Bedarf nach einem Begriff, der mehr umschreibt als ein Einzelge-

4 Siehe hierzu W. Kahl, Die Europäisierung des Verwaltungsrechts als Herausforderung an Systembildung und Kodifikationsidee, in: P. Axer/B. Grzeszick/W. Kahl/U. Mager/E. Reimer (Hrsg.), Das Europäische Verwaltungsrecht in der Konsolidierungsphase, Die Verwaltung, Beiheft 10, Berlin 2010, S. 39 ff.; weitergehend O. Mir Puigpelat, Die Kodifikation des Verwaltungsverfahrensrechts im Europäischen Verwaltungsverbund, in: J.-P. Schneider/F. Velasco Caballero (Hrsg.), Strukturen des Europäischen Verwaltungsverbunds, Die Verwaltung, Beiheft 8, Berlin 2009, S. 177 ff.; differenzierend C. Ladenburger, Evolution oder Kodifikation eines allgemeinen Verwaltungsrechts in der EU, in: H.-H. Trute/H. C. Röhl/ C. Möllers (Hrsg.), Allgemeines Verwaltungsrecht - zur Tragfähigkeit eines Konzepts, Tübingen 2008, S. 107 ff.; vgl. auch für das Umweltrecht H.-W. Rengeling, Die Kodifikation des Umweltrechts auf nationaler und europäischer Ebene: Chancen und Risiken für eine bessere Rechtsetzung und Umsetzung des EG-Umweltrechts, in: E. Bohne (Hrsg.), Ansätze zur Kodifikation des Umweltrechts in der Europäischen Union: Die Wasserrahmenrichtlinie und ihre Umsetzung in nationales Recht, Berlin 2005, S. $121 \mathrm{ff}$.

5 Vgl. F. Wieacker, Aufstieg, Blüte und Krisis der Kodifikationsidee, in: Festschrift für Gustav Boehmer, Bonn 1954. S. 34 (34); R. Herzog, Art. „Kodifikation“, in: H. Kunst/S. Grundmann (Hrsg.), Evangelisches Staatslexikon, Berlin 1966, Sp. 1074 (1074).

6 Vgl. B. Mertens, Gesetzgebungskunst im Zeitalter der Kodifikationen, Tübingen 2004, S. 325-354, insb. S. 326,334 f., 336 f., 342 f., 347 f.

7 H. Kindermann, Überlegungen zu einem zeitgemäßen Verständnis der Kodifikation, Rechtstheorie 10 (1979), S. 357 (358f.); vgl. auch R. Wabl, Vereinheitlichung oder bereichsspezifisches Verwaltungsverfahrensrecht?, in: W. Blümel (Hrsg.), Die Vereinheitlichung des Verwaltungsverfahrensrechts, Berlin 1984, S. 19 (19f.).

8 T. Bühler, Gewohnheitsrecht - Enquête - Kodifikation, Zürich 1977, S. 113-117; K. Schmidt, Die Zukunft der Kodifikationsidee, Heidelberg 1985, S. 17-21; H. Schulze-Fielitz, Theorie und Praxis parlamentarischer Gesetzgebung, Berlin 1988, S. 200-203; W. Kahl, Das Verwaltungsverfahrensgesetz zwischen Kodifikationsidee und Sonderrechtsentwicklung, in: W. Hoffmann-Riem/E. Schmidt-Aßmann (Hrsg.), Verwaltungsverfahren und Verwaltungsverfahrensgesetz, Baden-Baden 2002, S. 67 (102, 104). 
setz, ${ }^{9}$ eine konsolidierte Fassung ${ }^{10}$ oder eine sonst wie geartete Kompilation ${ }^{11}$ von Rechtsvorschriften. Zwar gibt es keinen Vorrang der Kodifikation vor anderen Regelungsarten. ${ }^{12}$ Allerdings ist die Kodifikation im Gegensatz zu anderen Gesetzen von ihrem Anspruch her grundsätzlicher. Ihr Grundansatz ist ein systematischer. Der von einer Kodifikation erfasste Regelungsbereich soll planvoll geordnet werden, so dass idealiter ein langlebiger Regelungsrahmen besteht. ${ }^{13}$ Damit ist wiederum eine gewisse, wenngleich aus den genannten Gründen relativierte, Vorstellung von Vollständigkeit verbunden, die zudem nicht für jede Kodifikation dieselbe sein kann.

\section{Typen}

Um den differenzierten Vollständigkeitsanspruch eines zeitgemäßen Kodifikationsverständnisses zum Ausdruck zu bringen, lassen sich vier Kodifikationstypen unterscheiden, die als Gegenbegriffe ihre Unterscheidungskraft gewinnen.

\section{Generalkodifikation - Bereichskodifikation}

In Hinblick auf den Vollständigkeitsanspruch betreffend den Regelungsgegenstand lassen sich Generalkodifikationen und Bereichskodifikationen unterscheiden. Eine Generalkodifikation erfasst einen Regelungsgegenstand rechtsgebietsübergreifend, d.h. für das Verwaltungsrecht, dass sie Regelungen trifft, die grundsätzlich für alle Bereiche des Besonderen Verwaltungsrechts gelten. ${ }^{14}$ Ein Beispiel ist das VwVfG, das im Immissionsschutzrecht wie im Wehrrecht, im Wasserrecht wie im Handwerksrecht zur Anwendung kommt. Eine Bereichskodifikation hingegen erfasst einen Regelungsgegenstand rechtsgebietsspezifisch. ${ }^{15}$ Diese Regelungsform ist dort verbreitet, wo der Regelungsgegenstand überhaupt nur rechtsgebietsspezifisch besteht, namentlich im Besonderen Verwaltungsrecht. Aber in den einzelnen besonderen Rechtsgebieten treten immer auch Regelungsbedürfnisse auf, die so oder so ähnlich auch in den anderen Rechtsgebieten bestehen; im Verwaltungsrecht sind dies vor allem Ver-

9 F.-J. Peine, Zur praktischen Bedeutung der Kodifikationsidee - dargestellt am Umweltrecht und am Gewerberecht, in: J. Ipsen/E. Schmidt-Jortzig (Hrsg.), Recht - Staat - Gemeinwohl. Festschrift für Dieter Rauschning, Köln u.a. 2001, S. 669 (669 f.).

10 In diesem Sinne wird der Begriff der Kodifikation im Unionsrecht gebraucht; siehe Interinstitutionelle Vereinbarung vom 20. Dezember 1994 über ein beschleunigtes Arbeitsverfahren für die amtliche Kodifizierung von Rechtstexten, ABl. EG Nr. C 102 vom 4.4.1996, S. 2: „Als amtliche Kodifizierung im Sinne dieses Arbeitsverfahrens gilt ein Verfahren mit dem Ziel, die zu kodifizierenden Rechtsakte aufzuheben und durch einen einzigen Rechtsakt zu ersetzen, der keine inhaltliche Änderung der betreffenden Rechtsakte bewirkt.“. So beispielsweise geschehen bei der Richtlinie 2011/92/EU des Europäischen Parlaments und des Rates vom 13. Dezember 2011 über die Umweltverträglichkeitsprüfung bei bestimmten öffentlichen und privaten Projekten (kodifizierter Text), ABl. EU Nr. L 26 vom 28.1.2012, S. $1 \mathrm{ff}$.

11 Vgl. Bühler, Kodifikation (Fn. 8), S. 67-69, 87-104.

12 Kindermann, Kodifikation (Fn. 7), S. 359; Schmidt, Kodifikationsidee (Fn. 8), S. 43.

13 Schulze-Fielitz, Gesetzgebung (Fn. 8), S. 201; Kahl, Europäisierung (Fn. 4), S. 56; Peine, Kodifikationsidee (Fn. 9), S. 677.

$14 \mathrm{Kahl}$, Kodifikationsidee (Fn. 8), S. 84.

15 Kahl, Kodifikationsidee (Fn. 8), S. 86. 
fahrensfragen. Sie können dann in einer Generalkodifikation wie dem VwVfG allgemein geregelt werden. Es können aber auch für einzelne Bereiche Sonderregelungen in die Generalkodifikation aufgenommen werden oder für einzelne Gebiete gleich ganze Bereichskodifikationen errichtet werden. ${ }^{16}$ Im letzten Fall, für den das Sozialgesetzbuch X (SGB X) ein Beispiel bildet, eignet der Bereichskodifikation eine Zwitterstellung, denn aus der Perspektive der Generalkodifikation (hier: des VwVfG) ist sie nicht so sehr Kodifikation als vielmehr Sonderregelung. ${ }^{17}$ Der Kodifikationsbegriff ist somit blickwinkelbedingt relativ.

\section{Gesamtkodifikation - Teilkodifikation}

Sowohl bei General- als auch bei Teilkodifikationen ist hinsichtlich der inhaltlichen Vollständigkeit zwischen Gesamtkodifikationen und Teilkodifikationen zu differenzieren. Eine Gesamtkodifikation will alle, zumindest alle wesentlichen Rechtsfragen regeln, die Teilkodifikation hingegen will nur einzelne Regelungsbedürfnisse des Regelungsgegenstandes erfüllen. ${ }^{18}$ Die Gesamtkodifikation erinnert damit an das alte, unerreichbare Kodifikationsideal. Dessen Verabschiedung macht aber weder den Begriff noch die Idee der Gesamtkodifikation überflüssig, die darin zu sehen ist, dass sich der Gesetzgeber mit einer Gesamtkodifikation abschließend zu einer Regelungsmaterie äußert. ${ }^{19}$ Bedeutung erlangt dies insbesondere im Rahmen der konkurrierenden Gesetzgebung (Art. 70, 72 GG), denn hier kommt es entscheidend darauf an, ob eine bundesgesetzliche Regelung abschließend sein soll. Nur wenn dem nicht so ist verbleibt den Ländern eine eigene Gesetzgebungsbefugnis, andernfalls ist sie gesperrt (Art. 72 Abs. 1 GG). ${ }^{20}$ Der abgeschlossene Regelungskomplex muss zwar nicht die Gestalt einer Kodifikation haben, allerdings ist dies häufig der Fall. Da die Abgeschlossenheit eines Regelungskomplexes aber nicht nur durch positive Regelung, sondern auch durch „beredtes Schweigen“ erfolgen kann, ${ }^{21}$ verschwimmt allerdings ein Stück weit die Grenze zur Teilkodifikation, die keine Sperrwirkung zu entfalten vermag. ${ }^{22}$

\section{Allgemeine Teile als Essenz einer Kodifikation}

Die Essenz jeder Kodifikation ist die Möglichkeit eines Allgemeinen Teils, des berühmten „vor die Klammer Ziehens“ von Regelungsgehalten, die in unterschiedli-

16 Zum Ganzen Wahl, Vereinheitlichung (Fn. 7), S. 26-50.

17 Kahl, Kodifikationsidee (Fn. 8), S. 86-88.

18 Kahl, Kodifikationsidee (Fn. 8), S. 84.

19 Ohne dass damit alle Rechtsfragen geklärt sein müssten, geschweige denn könnten.

20 BVerfGE 102, 99 (114f.); 109, 190 (229 f.); S. Oeter, in: H. von Mangoldt/F. Klein/C. Starck (Hrsg.), Kommentar zum Grundgesetz, Bd. 2, 6. Aufl., München 2010, Art. 72 Rn. 70-74, insb. Rn. 73.

21 R. Stettner, in: H. Dreier (Hrsg.), Grundgesetz, Bd. II, Supplementum 2007, Tübingen 2007, Art. 72 Rn. 41.

22 Vgl. BVerfGE 56, 110 (119); T. Maunz, in: ders./G. Dürig, Grundgesetz, München, Loseblatt (Stand: April 2012), Art. 74 Rn. 36 f. 
chen von der Kodifikation erfassten Situationen wiederkehren. Wegen ihres systematischen Ansatzes ${ }^{23}$ setzt jede Kodifikation eine Systematisierung des in ihr zusammengefassten Rechtsstoffs voraus. ${ }^{24}$ Diese systematische Durchdringung wiederum ermöglicht die regelungstechnische Bildung Allgemeiner Teile. ${ }^{25}$ Eine Kodifikation muss zwar nicht explizit einen Allgemeinen Teil ausweisen. Sie kann Regelungen abschnittsweise vor die Klammer ziehen oder auf ein Zusammenfassen gänzlich verzichten und die gleichartigen Regelungen an den unterschiedlichen Stellen stets wiederholen. Die für eine Kodifikation nötige Systematisierung ermöglicht allerdings die Bildung eines Allgemeinen Teils und weckt das Bewusstsein hierfür. Die Möglichkeit der Bildung eines Allgemeinen Teils durch die einer Kodifikation vorausgehende Systematisierung kann in einer weitestgehenden Kongruenz von Kodifikation und Allgemeinem Teil gipfeln, wenn eine Kodifikation im Schwerpunkt nur allgemeine Regelungen trifft, wie es vor allem - aber nicht ausschließlich - für Generalkodifikationen typisch ist. Im Verwaltungsrecht ist auch insofern das VwVfG wieder das erste Beispiel.

Die Hervorhebung des Konnexes von Kodifikation und Allgemeinem Teil erleichtert den Zugang zu und verdeutlicht drei wichtige Aspekte der Kodifikationsdiskussion. Erstens ruft sie die jeder Kodifikation zur Verarbeitung aufgegebene Spannungslage zwischen übersichtlicher, konsequenter Verallgemeinerung und spezielle Sachgesetzlichkeiten berücksichtigender, Flexibilität ermöglichender Sonderregelung ins Bewusstsein ${ }^{26}$ und zwingt dadurch zur Auseinandersetzung mit allgemeinen Einwänden gegen die Kodifikationsidee in heutiger Zeit. ${ }^{27}$ Zweitens schärft sie den Blick für die Einwände, die gegen die Kodifikationsidee speziell im Öffentlichen Recht vorgebracht werden. Hier wird die Möglichkeit von Kodifikationen einerseits und Allgemeinen Teilen andererseits zwar gesondert, aber mit im Wesentlichen gleichen Argumenten bestritten, was ebenfalls der Auseinandersetzung bedarf. ${ }^{28}$ Drittens erleichtert die Betonung des Konnexes von Kodifikation und Allgemeinem Teil das Verständnis dafür, wieso aus Sicht der Verwaltungsrechtswissenschaft Kodifikationen auch eine wissenschaftliche Aufgabe sind. Aus der Perspektive der Verwaltungsrechtswissenschaft lassen sich nämlich durch Gesetzgebung hervorgebrachte Allgemeine Teile von dem Allgemeinen Teil des Verwaltungsrechts als wissenschaftlichem

23 Siehe oben B. I.

24 H. Schneider, Gesetzgebung, 3. Aufl., Heidelberg 2002, Rn. 432; Kahl, Europäisierung (Fn. 4), S. 56. Siehe auch unten D. III.

25 D. Medicus, Allgemeiner Teil des BGB, 10. Aufl., Heidelberg 2010, Rn. 19; K. F. Röhl/H. C. Röhl, Allgemeine Rechtslehre, 3. Aufl., Köln, München 2008, S. 439, siehe auch S. 232.

26 In Hinblick auf Allgemeine Teile klassisch einerseits P. Heck, Der Allgemeine Teil des Privatrechts, AcP 146 (1941), S. 1 ff., andererseits F. Wieacker, Privatrechtsgeschichte der Neuzeit, 2. Aufl., Göttingen 1967, S. 475 f. Zusammenstellung der Argumente beider Seiten für das Verwaltungsverfahrensrecht bei Wahl, Vereinheitlichung (Fn. 7), S. $27 \mathrm{f}$.

27 Siehe unten D. I. 1.

28 Siehe unten D. I. 2. 
Projekt unterscheiden. ${ }^{29}$ Die Bezeichnung jeweils als „Allgemeiner Teil“ fordert Fragen nach Selbststand, Wechselbeziehungen und Grenzen der Beeinflussung von bzw. zwischen Gesetzgebung und Rechtswissenschaft heraus, deren Beantwortung zur Konkretisierung der Rolle der beiden genannten Akteure im Rahmen von Kodifizierungsprozessen beiträgt. ${ }^{30}$ Bevor auf diese Punkte eingegangen wird, sollen aber zunächst kurz die Funktionen einer Kodifikation in den Blick genommen werden.

\section{Funktionen der Kodifikation}

Kodifikationen haben unterschiedliche Funktionen. ${ }^{31}$ Besonders bedeutsam ist die Rechtsvereinheitlichungsfunktion. ${ }^{32}$ Mittels einer Kodifikation soll das bestehende Regelungsgefüge eine doppelte Systematisierung erfahren: eine inhaltliche in Form einer sachlichen Strukturierung und eine äußerliche in Form einer ordnenden $\mathrm{Zu}$ sammenfassung bisher verstreuter Regelungen, wobei beide Systematisierungsleistungen stärker oder schwächer ausgeprägt sein können. ${ }^{33}$ Durch die Systematisierungsleistung erfüllt eine Kodifikation insbesondere eine Deregulierungsfunktion und erhöht die Übersichtlichkeit hinsichtlich der einschlägigen normativen Vorgaben, wodurch die Rechtsarbeit entlastet, die Rechtssicherheit erhöht und durch die so beförderte Nachvollziehbarkeit die Akzeptanz für rechtliche Entscheidungen der Verwaltung und der Gerichte erhöht wird. ${ }^{34}$ Darüber hinaus eignet der Kodifikation eine doppelte Innovationsfunktion. ${ }^{35}$ Einerseits dient sie als Vorbild für andere Regelungsvorhaben, sei es in spezielleren Regelungsmaterien oder im Ausland, bietet also Orientierung und fördert Stabilität. Andererseits nimmt sie Innovationen auf, insbesondere kann sie in besonderen Regelungsmaterien erprobte Figuren in ihre Systematik integrieren und den bisherigen Regelungsstand dadurch schrittweise fortentwickeln. Zudem kann sie als übergeordnete „Schaltstelle“36 die Umsetzung von (innovativem) Unionsrecht erleichtern sowie die Rezeption von durch Rechtsvergleichung gewonnenen Erkenntnissen mit breiter Regelungswirkung ermöglichen. Ne-

29 Weiterführend J. Kersten/S.-C. Lenski, Die Entwicklungsfunktion des Allgemeinen Verwaltungsrechts, Die Verwaltung 42 (2009), S. 501 (502f.).

30 Siehe unten D. III.

31 Ausführlich zum Ganzen Kahl, Kodifikationsidee (Fn. 8), S. 89-98; ders., Europäisierung (Fn. 4), S. 56-58. Am Beispiel eines Umweltgesetzbuchs M. Kloepfer, Sinn und Gestalt des kommenden Umweltgesetzbuchs, UPR 2007, S. 161 (164-167); D. Sellner, Der systematische Ertrag einer Kodifikation für das allgemeine Verwaltungsrecht am Beispiel des Umweltgesetzbuches, in: Trute et al. (Hrsg.), Allgemeines Verwaltungsrecht (Fn. 4), S. $191 \mathrm{ff}$.

32 Vgl. P. Noll, Gesetzgebungslehre, Reinbek bei Hamburg 1973, S. 215 f.

33 Vgl. mit Beispielen Schulze-Fielitz, Gesetzgebung (Fn. 8), S. 89-94.

34 Vgl. am Beispiel des VwVfG BT-Drs. 7/910, S. 28 f.; U. Stelkens, Kodifikationssinn, Kodifikationseignung und Kodifikationsgefahren im Verwaltungsverfahrensrecht, in: H. Hill/K-P. Sommermann/U. Stelkens/J. Ziekow (Hrsg.), 35 Jahre Verwaltungsverfahrensgesetz - Bilanz und Perspektiven, Berlin 2011, S. 271 (273 f.); W. Hoffmann-Riem, Verwaltungsverfahren und Verwaltungsverfahrensgesetz, in: ders./Schmidt-Aßmann (Hrsg.), Verwaltungsverfahren (Fn. 8), S. 9 (13 f.).

$35 \mathrm{Kahl}$, Europäisierung (Fn. 4), S. 57.

36 Siehe unten D. I. 1. b). 
ben dieser primär positivrechtlichen Innovationsfunktion besteht zudem eine ganz erhebliche Impulsfunktion für die Wissenschaft. ${ }^{37}$ Schon das bloße Kodifikationsvorhaben befördert die wissenschaftliche Auseinandersetzung mit und Durchdringung von einem Rechtsgebiet und stößt weitergehende Überlegungen und Kooperationen an, die zu wissenschaftlichen Erträgen führen, die unabhängig von einem etwaigen Inkrafttreten der Kodifikation Bedeutung und Wert haben (Kodifikation als Prozess). ${ }^{38}$

\section{Kodifikation als Aufgabe von Gesetzgebung und Wissenschaft}

Kodifikationen sind stets ein Kraftakt. Ob sie der Mühen wert sind hängt davon ab, was gegen sie sprechen kann. Aufmerksamkeit verdient daneben, wer wie an ihrer Entstehung beteiligt ist.

\section{Einwände gegen die Kodifikationsidee}

\section{Generelle Einwände gegen die Kodifikationsidee}

\section{a) Grundsätzliche Einwände}

Der grundsätzlichste Einwand gegen die Kodifikationsidee geht dahin, dass Kodifikationen den heutigen Regelungsbedürfnissen nicht mehr gerecht werden könnten. ${ }^{39}$ In einem auf gesellschaftliche Offenheit, Pluralität und Demokratie gestützten Gemeinwesen in der modernen Welt wolle Gesetzgebung das soziale Leben in Verarbeitung der pluralistischen Interessen bewusst gestalten und die Herausforderungen der fortscheitenden technischen Entwicklung normativ bewältigen. Beides erfordere kurzfristige und punktuelle gesetzgeberische Interventionen, die durch wechselnde politische Mehrheiten unstet würden. Diese modernen Regelungsbedürfnisse könnten nur durch das Einzelgesetz erfüllt werden. Darüber hinaus bereite die Hinwendung von einer konditionalen zu einer stärker finalen Gesetzgebung Probleme für eine Kodifikationsgesetzgebung. ${ }^{40}$

38 Voßkuble, Prozeß (Fn. 1), S. 77.

39 Hierzu und zum Folgenden Kübler, Kodifikation (Fn. 3), S. 645 ff., insb. S. 647-651; J. Esser, Gesetzesrationalität im Kodifikationszeitalter und heute, in: H.-J. Vogel/J. Esser, 100 Jahre oberste deutsche Justizbehörde, Recht und Staat 470, Tübingen 1977, S. 13 ff., insb. S. 14-18, 24-26, 31-34; O. Lepsius, Themen einer Rechtswissenschaftstheorie, in: M. Jestaedt/O. Lepsius (Hrsg.), Rechtswissenschaftstheorie, Tübingen 2008, S. 1 (42 f.); vgl. auch F. Ossenbühl, Gesetz und Recht - Die Rechtsquellen im demokratischen Rechtsstaat, in: J. Isensee/P. Kirchhof (Hrsg.), Handbuch des Staatsrechts der Bundesrepublik Deutschland, Bd. V, 3. Aufl., Heidelberg u.a. 2007, \$ 100 Rn. 22; sowie die Skepsis bei H. Schulze-Fielitz, Einheitsbildung durch Gesetz oder Pluralisierung durch Vollzug, in: Trute et al. (Hrsg.), Allgemeines Verwaltungsrecht (Fn. 4), S. 135 (159f.). Allgemein zu den Bedingungen „moderner" Gesetzgebung vgl. G. F. Schuppert, Governance und Rechtsetzung, Baden-Baden 2011, S. 44-79.

40 R. Breuer, Empfiehlt es sich, ein Umweltgesetzbuch zu schaffen, gegebenenfalls mit welchen Regelungsbereichen? Gutachten B für den 59. Deutschen Juristentag, in: Ständige Deputation des Deutschen Juristentages (Hrsg.), Verhandlungen des 59. Deutschen Juristentages, Bd. I, München 1992, S. B 37-B 42 . 
Richtig ist zwar, dass die heutigen Regelungsbedürfnisse zum weitaus größten Teil durch Einzelgesetze befriedigt werden und oftmals auch nur durch sie befriedigt werden können. Gleichwohl lässt dies die Kodifikationsidee nicht vollends obsolet werden. Zum einen geht die Grundsatzkritik von einem überkommenem Kodifikationsbegriff aus, dessen Unzulänglichkeiten mit einer differenzierten Typenbildung begegnet werden kann. ${ }^{41}$ Zum anderen ist die vollständige Aufgabe der Kodifikationsidee nicht nur aus idealistischen Gründen unbefriedigend, sondern auch wider die positivrechtliche Realität. Denn dass es Kodifikationen gibt, dass sie stetig und durchaus planvoll weiterentwickelt werden und dass neue Kodifikationen von Zeit zu Zeit immer wieder in Angriff genommen werden, ist ein nicht von der Hand zu weisender Befund. ${ }^{42}$ Der Abgesang auf die Kodifikation ist daher - wie umgekehrt auch ihre Überhöhung zum Ideal - ungeeignet, die Anforderungen an moderne Gesetzgebung zutreffend zu charakterisieren.

\section{b) Europäisierung als Einwand}

Eng verbunden mit den grundsätzlichen Einwänden, aber auch Schnittmengen zu den sogleich zu behandelnden regelungspraktischen Einwänden aufweisend, also gleichsam zwischen ihnen stehend, wird die Dynamik der Europäisierung der Rechtsordnung als Kodifikationshindernis gesehen. Im Verwaltungsrecht war dieser Einwand vor allem in der Diskussion um ein Umweltgesetzbuch (UGB) anzutreffen. Da das Unionsrecht unhintergehbare Vorgaben für das nationale Recht aufstelle sei eine nationale Kodifikation überhaupt erst möglich, wenn das hinter ihr stehende Unionsrecht eine hinreichende Strukturiertheit erlangt habe, gleichsam selbst kodifikationsreif sei, ${ }^{43}$ und selbst dann laufe eine nationale Kodifikation stets Gefahr, dass ihr Regelungskonzept durch punktuelle unionsrechtliche Regelungsvorstöße überholt werde.

So gewichtig die unionsrechtlichen Vorgaben für die nationale Gesetzgebung sind, schließen sie Kodifikationen gleichwohl nicht kategorisch aus. Zum einen verbleiben den nationalen Gesetzgebern auch in unionsrechtlich determinierten Regelungsgebieten stets Spielräume zur eigenen Gestaltung. ${ }^{44}$ Zum anderen spricht nichts dagegen, bisher nur punktuell gebliebene unionsrechtliche Vorgaben als Fixpunkte in eine nationale Kodifikation zu integrieren und damit eventuell sogar auf den weiteren

41 Siehe oben B.

42 So auch F. Reimer, Das Parlamentsgesetz als Steuerungsmittel und Kontrollmaßstab, in: W. Hoffmann-Riem/E. Schmidt-Aßmann/A. Voßkuhle (Hrsg.), Grundlagen des Verwaltungsrechts, Bd. I, 2. Aufl., München 2012, $\mathbb{S} 9$ Rn. 22 m. Nachw.; Peine, Kodifikationsidee (Fn. 9), S. 677 f.; rechtsvergleichend J. Basedow, Das BGB im künftigen europäischen Privatrecht: Der hybride Kontext, AcP 200 (2000), S. 445 (466).

43 K. Hansmann, Empfiehlt es sich, ein Umweltgesetzbuch zu schaffen, gegebenenfalls mit welchen Regelungsbereichen?, in: Ständige Deputation des Deutschen Juristentages (Hrsg.), Verhandlungen des 59. Deutschen Juristentages, Bd. II, München 1992, S. N 8 (N 13-N 16).

44 C. Calliess, Vorgaben für ein Umweltgesetzbuch: Europarecht, in: M. Kloepfer (Hrsg.), Das kommende Umweltgesetzbuch, Berlin 2007, S. 35 (40 f.). 
Entwicklungsprozess des Unionsrechts selbst einzuwirken. ${ }^{45}$ Die Problematik liegt weniger in der Struktur des Mehrebenensystems als vielmehr im fehlenden Gestaltungswillen nationaler Gesetzgeber, was freilich nicht ganz unverständlich ist, denn die - oftmals nur punktuellen - Vorgaben des Unionsrechts setzen nationale Kodifikationen durchaus unter ständigen Anpassungsdruck, wenn sie nicht einfach inhaltlich überholt und damit entwertet werden wollen. ${ }^{46}$ Das kann als Last gescheut, aber auch als Chance wahrgenommen werden. Immerhin ermöglichen es Kodifikationen wegen ihrer Breitenwirkung, unionsrechtliche Vorgaben durch Änderung nur eines Gesetzes umzusetzen und so als „Schaltstelle“ der Unionsrechtsumsetzung für eine Vielzahl von Regelungsmaterien zu fungieren. ${ }^{47}$ Schaltstelle kann eine Kodifikation aber auch insofern sein, als dass sie - ganz im Sinne eines Allgemeinen Teils - für wiederkehrende Regelungsbedürfnisse Stammregelungen enthält, auf die sektorale Einzelgesetze Bezug nehmen können. ${ }^{48}$ Dass auf diese Weise unionsrechtliche Impulse systematisch aufgenommen und in eine Kodifikation integriert werden können, zeigt die deutsche Umsetzung der EU-Dienstleistungsrichtlinie, ${ }^{49}$ die zu einer vorbildlichen, in ihrer Reichweite unionsrechtlich nicht geforderten Änderung des VwVfG geführt hat, ${ }^{50}$ statt durch eine Eins-zu-Eins-Umsetzung neues Sonderrecht zu schaffen. Derartige Umsetzungen, die nahezu zwangsläufig mit der zusätzlichen Veränderung bisheriger nationaler Regelungsstrukturen (spill-over-Effekt) einhergehen, setzen allerdings eine fortgeschrittene Durchdringung des Rechtsstoffs voraus, die planvolle und strukturierte Änderungen überhaupt erst möglich macht und die erheblich von wissenschaftlichen Vorarbeiten profitiert, weshalb wissenschaftliche

45 M. Kloepfer, Sinn und Gestalt (Fn. 31), S. 164; K. Meßerschmidt, Das europäisierte Umweltgesetzbuch, in: Umweltgesetzbuch und Gesetzgebung im Kontext, München 2008, S. 46 (51 f., 55 f., 58).

46 W. Kahl, Das Verhältnis Ordnungsrecht - „weiches Recht“ aus Sicht der Wissenschaft, in: M. Kloepfer (Hrsg.), Umweltgesetzbuch (Fn. 44), S. 113 (120-122); M. Burgi, Übergreifende Regelung des Rechts der Regulierungsverwaltung - Realisierung der Kodifikationsidee?, NJW 2006, S. 2439 (2441f.).

47 A. Debus, Vom Wert einer Kodifikation des Umweltrechts, VerwArch 100 (2009), S. 21 (35). Vgl. auch R. Wahl, Herausforderungen und Antworten: Das Öffentliche Recht der letzten fünf Jahrzehnte, Berlin 2006, S. 38 f., in Bezug auf die Transformation von Vorgaben des Verfassungsrechts über einen sachgebietsübergreifenden Allgemeinen Teil des Verwaltungsrechts in alle Bereiche des Besonderen Verwaltungsrechts hinein.

48 Siehe auch unten F. II sowie F.-J. Peine, Entwicklung des Verwaltungsverfahrensrechts - ein Forschungsprogramm, LKV 2012, S. 1 (6 f.). Für das Umweltverwaltungsrecht befürwortend G. Winter, Das Umweltgesetzbuch - Überblick und Bewertung, ZUR 2008, S. 337 (339 f., 342 f.); W. Köck, Das Scheitern des UGB: Wie geht es weiter?, ZUR 2009, S. 57 (58).

49 Richtlinie 2006/123/EG des Europäischen Parlaments und Rates vom 12.12.2006 über Dienstleistungen im Binnenmarkt, ABl. EU Nr. L 376 vom 27.12.2006, S. 36 ff.

50 Näher H. Schmitz/L. Prell, Verfahren über eine einheitliche Stelle - Das Vierte Gesetz zur Änderung verwaltungsverfahrensrechtlicher Vorschriften, NVwZ 2009, S. 1 ff.; dies., Europäische Verwaltungszusammenarbeit - Neue Regelungen im Verwaltungsverfahrensgesetz, NVwZ 2009, S. $1121 \mathrm{ff}$; Kahl, Europäisierung (Fn. 4), S. 77-81; ders., Entwicklung des Rechts der Europäischen Union und der Rechtsprechung des EuGH, in: Hill et al. (Hrsg.), 35 Jahre (Fn. 34), S. 111 (129-131); kritisch C. Ernst, Die Einführung eines einheitlichen Ansprechpartners i. S. der EU-Dienstleistungsrichtlinie durch das 4. Gesetz zur Änderung verwaltungsverfahrensrechtlicher Vorschriften, DVBl. 2009, S. 653 ff. 
Systembildung ${ }^{51}$ eine Strategie ist, Kodifikationsbestrebungen auch unter dem Eindruck der Europäisierung zu unterstützen. ${ }^{52}$

\section{c) Regelungspraktische Einwände}

Die Kodifikation trifft ferner auf regelungspraktische Bedenken. ${ }^{53}$ Wie ihr Konnex zu Allgemeinen Teilen besonders deutlich werden lässt, ${ }^{54}$ läuft sie von ihrer Grundanlage her Gefahr, sachlich Verschiedenes gleich zu regeln, in diesem Zuge innovative und/oder flexible punktuelle Neuregelungen zu blockieren sowie im Ganzen zu änderungsresistent zu werden und dadurch dem Schicksal zwangsläufiger Veralterung ausgeliefert zu sein. Diese Bedenken sind nicht von der Hand zu weisen und müssen bei der wie auch immer gearteten Befassung mit Kodifikationen als Mahnung stets präsent bleiben. Nicht alle Regelungsbereiche eignen sich zur Kodifikation oder bleiben dauerhaft hierfür geeignet. Zutreffend wird deshalb Kodifikationsgesetzgebung heute als ein dialektischer Prozess der fortwährenden „Dekodifikation“ und „ReKodifikation" beschrieben. ${ }^{55}$ Kodifikationen müssen mit der Zeit gehen, d.h. es müssen zur Sicherstellung von sachangemessenen Regelungen und hinreichender Flexibilität wenn nötig Regelungsbereiche aus ihnen ausgegliedert oder außerhalb von ihnen neu errichtet werden, so dass ein experimentelles Lernen stattfinden kann. Wurden hinreichende Erfahrungen mit den Sondergesetzen gesammelt und erlaubt es der Stand der dogmatischen Durchdringung dieser Materien, sind die Regelungen nach Möglichkeit wieder in die Kodifikation einzupassen, wobei sich im Zuge dessen selbstredend auch die Kodifikation an sie anpassen muss. In diesen Prozessen wird nie alles auf einmal zu haben sein, so dass sich insbesondere ein schrittweises Vorgehen (gestufte Kodifikation) anbieten kann. ${ }^{56}$ Dass trotz der Betonung von spezifischen Regelungsbedürfnissen die Kodifikation immer wieder eine große Anziehungskraft auf die Sondergesetze auszuüben vermag, wird etwa auch daran deutlich, dass der Großteil der von Josef Esser im Jahr 1977 zur Stützung seiner These, moderne Gesetzgebung vollziehe sich nur noch in Form sachangemessener Sondergesetze, ${ }^{57}$

51 Hierzu unten D. III.

52 Kahl, Entwicklung (Fn. 50), S. 137; ders., Europäisierung (Fn. 4), S. 55 f.

53 Hierzu auch Kahl, Kodifikationsidee (Fn. 8), S. 98-101 m. Nachw.

54 Siehe oben B. III.

55 Schmidt, Kodifikationsidee (Fn. 8), S. 48-54; Schulze-Fielitz, Gesetzgebung (Fn. 8), S. 202 f.; vgl. auch Noll, Gesetzgebungslehre (Fn. 32), S. 214-218 sowie für die europäische Ebene Kahl, Europäisierung (Fn. 4), S. 40 f., 72 f. Skeptisch hingegen S. Meder, Die Krise des Nationalstaates und ihre Folgen für das Kodifikationsprinzip, JZ 2006, S. 477 (483 f.).

56 Kahl, Kodifikationsidee (Fn. 8), S. 103; Sellner, Ertrag (Fn. 31), S. 194 f.; K. von Lewinski, Das Umweltgesetzbuch in den Augen von Thibaut und Savigny, in: Umweltgesetzbuch und Gesetzgebung (Fn. 45), S. 1 (12 f.); für das europäische Verwaltungsrecht Kahl, Europäisierung (Fn. 4), S. 61-64.

57 Vgl. Esser, Gesetzesrationalität (Fn. 39), S. 37. 
angeführten Gesetze oder Gesetzesmaterien mittlerweile in das BGB integriert sind. ${ }^{58}$

\section{Spezielle Einwände gegen die Kodifikationsidee im Öffentlichen Recht}

Unabhängig von den generellen Einwänden wird die Kodifikationsidee bisweilen speziell im Öffentlichen Recht als deplatziert angesehen. Anders als das Zivil- und das Strafrecht sei das Öffentliche Recht aufgrund des Stufenbaus der Rechtsordnung und der bundesstaatlichen Struktur der Bundesrepublik geprägt vom Umgang mit einer Vielzahl von Rechtsquellen unterschiedlicher Hierarchiestufen und Herkunft. ${ }^{59}$ Diese unterschiedliche Grundstruktur führe dazu, dass Kodifikationen im Allgemeinen und die regelungstechnische Aussonderung von Allgemeinen Teilen im Besonderen in dem mit nur einer normativen Rangstufe befassten Zivil- und Strafrecht (im Horizontalen) hohe Strukturierungs- und Rationalisierungsleistungen erbringen würden. ${ }^{60}$ Kodifikationen und Allgemeine Teile wären aber eben nur in derartigen normativen Ausgangslagen, d.h. innerhalb einer Rangordnungsstufe des Stufenbaus der Rechtsordnung, möglich. ${ }^{61}$ Deshalb seien Kodifikation und Allgemeiner Teil für das normativ vielschichtige Öffentliche Recht die falschen Kategorien, denn hier müssten und würden die Strukturierungsleistungen wegen des Stufenbaus der Rechtsordnung im Vertikalen erfolgen. ${ }^{62}$

Die Kritik verfängt jedoch nicht. Im Öffentlichen Recht ist die Kodifikationsidee nicht aus strukturellen Gründen deplatziert und zwar unabhängig von der zu schroffen Gegenüberstellung von Zivil-/Strafrecht und Öffentlichem Recht ${ }^{63}$ und unter Anerkennung des Umstandes, dass im Öffentlichen Recht ein stärkeres Zusammenspiel von Recht unterschiedlicher Hierarchiestufen und Herkunft herrscht. Zum einen wird die Möglichkeit von Bereichs- und Teilkodifikationen nicht bestritten, sondern nur die Bezeichnung „Kodifikation“ für unpassend gehalten. ${ }^{64}$ Insofern sind nur die Begrifflichkeiten umstritten. Da aber mittlerweile der mit einer Kodifikation verbundene Vollständigkeitsanspruch, wie gezeigt, ganz generell relativiert ist, wird

58 AGB-Gesetz (heute: $\mathbb{\int} \mathbb{S} 305 \mathrm{ff}$. BGB); Haustürwiderrufsgesetz (heute: $\mathbb{\$} \$ 312 \mathrm{ff}$. BGB); Abzahlungsrecht (heute: $\mathbb{S} 506 \mathrm{ff}$. BGB). Das Reiseveranstaltungsrecht wurde sogar direkt in das BGB integriert $(\mathbb{S} 651$ aff. BGB). Allein die Haftung für fehlerhafte Produkte ist heute noch in einem Sondergesetz (Produkthaftungsgesetz) geregelt.

59 Lepsius, Rechtswissenschaftstheorie (Fn. 39), S. 27 f.

60 O. Lepsius, Hat die Europäisierung des Verwaltungsrechts Methode? Oder: Die zwei Phasen der Europäisierung des Verwaltungsrechts, in: Axer et al. (Hrsg.), Konsolidierungsphase (Fn. 4), S. 179 (196).

61 Lepsius, Methode (Fn. 60), S. 196, 199; ders., Rechtswissenschaftstheorie (Fn. 39), S. 28.

62 Lepsius, Methode (Fn. 60), S. 196 f.; ders., Rechtswissenschaftstheorie (Fn. 39), S. 28 f.

63 Zivil- und Strafrecht sind keinesfalls monolithische Blöcke bar jeder vertikalen normativen Verflechtung. Die vertikalen Beziehungsgefüge werden vor allem im Zivilrecht deutlich. Konstitutionalisierung und mehr noch Europäisierung sind keine exklusiv öffentlich-rechtlichen Phänomene, sondern wirken auch vielfältig und intensiv etwa auf das BGB ein. Unterhalb des Gesetzesrechts stehen - unabhängig von ihrer rechtsquellentheoretischen Einordnung - im Zivilrecht beispielsweise AGB und Tarifverträge.

64 Vgl. Lepsius, Methode (Fn. 60), S. 198. 
hier für eine Beibehaltung der Bezeichnung Kodifikation mit Präzisierung durch die verschiedenen Kodifikationstypen plädiert. ${ }^{65} \mathrm{Zum}$ anderen vermag nicht einzuleuchten, wieso Kodifikationen respektive Allgemeine Teile nur auf der Ebene einer einzigen Rangstufe im Stufenbau der Rechtsordnung sinnvoll oder gar möglich sein sollen. ${ }^{66}$ Allgemeine Regelungen können auch in hierarchisch strukturierten Normgefügen getroffen werden. Die Stellung einer Norm auf einer Rangstufe sagt ja nur etwas über ihren Erzeugungszusammenhang oder ihre derogatorische Kraft gegenüber anderen Normen aus. Die entscheidende Frage ist, ob einer der Rechtserzeugungsakteure die Kompetenz zum Erlass einer Kodifikation respektive eines Allgemeinen Teils hat. Das „Problem“ ist nicht die vertikale Struktur der Rechtsordnung, sondern die konkrete Verteilung der Rechtsetzungskompetenzen. Diese stellt das Öffentliche Recht tatsächlich vor Herausforderungen, die Zivil- und Strafrecht in diesem Maße nicht kennen, und erschwert zweifelsohne die Kodifikationsgesetzgebung. Doch haben sich auch hier bereits Strategien zur Handhabung des Kompetenzproblems entwickelt, sei es die Simultangesetzgebung von Bund und Ländern im Verwaltungsverfahrensrecht, ${ }^{67}$ sei es die Option einer Kompetenzneuordnung, wie sie etwa im Zuge der Föderalismusreform I zur Ermöglichung einer Kodifikation des Umweltrechts bereits tatsächlich vorgenommen wurde. ${ }^{68}$ Aus diesen Gründen ist die Kodifikationsidee auch für das Öffentliche Recht weiterhin tauglich.

\section{Die Rolle der Gesetzgebung}

Kodifikationsgebung ist Gesetzgebung und als solche vornehmste Aufgabe des Parlaments. Dem Gesetzgeber obliegt die (politische) Entscheidung darüber, was geregelt werden soll, ob eine Kodifikation oder Einzelgesetze erlassen werden und welchen Inhalt sie haben soll(en). Der politische Entschluss zur Kodifikationsgesetzgebung setzt dabei - nachdem eine Regelung überhaupt in Betracht gezogen wird zwei Schritte voraus. ${ }^{69}$ Zunächst muss der Gesetzgeber die Kodifikationsfähigkeit, anders gewendet die Kodifikationsreife der avisierten Materie bewerten, d.h. der Frage nachgehen, ob die Materie übergreifenden Regelungen überhaupt zugänglich ist. Die Bewertung obliegt ihm allein, wenngleich er sie ohne den Rückgriff auf Vorarbeiten Dritter (Ministerialbürokratie, Wissenschaft, Deutscher Juristentag u.a.) nicht sinnvoll wird vornehmen können. Der zweite Schritt ist die Bewertung der Kodifikationsbedürftigkeit, d.h. der Frage, ob eine Kodifikation das politisch „richtige" Regelungsinstrument ist, ob sie die beabsichtigten Wirkungen erreichen kann,

65 Siehe oben B.

66 So aber Lepsius, Methode (Fn. 60), S. 196 f., 198 f.

67 Hierzu unten F. IV.

68 Gesetz zur Änderung des Grundgesetzes vom 28.8.2006, BGBl. I, S. 2034. Zum Hintergrund der Ermöglichung einer Kodifikation des Umweltrechts siehe BT-Drs. 16/813, S. 8 f., 11, 15, 21; BR-Drs. 178/06, S. 16 f., 24, 35, 51.

69 Hierzu Kahl, Kodifikationsidee (Fn. 8), S. 101 f.; Burgi, Regulierungsverwaltung (Fn. 46), S. 2442. 
ob der Aufwand einer Kodifikation im rechten Verhältnis zu ihrem Nutzen steht, ob ihre Vorteile die Nachteile überwiegen etc. Die Bewertung der Kodifikationsbedürftigkeit ist mithin eine politische Gesamtbetrachtung unter qualitativen und quantitativen Gesichtspunkten, ${ }^{70}$ in der auch die Gesetzesfolgenabschätzung ihren Platz hat. $^{71}$

Sofern Kodifikationsfähigkeit und Kodifikationsbedürftigkeit bejaht werden und in einem politischen Entschluss zur Kodifikationsgesetzgebung münden, beginnt erst der legislatorische Kraftakt, den eine Kodifikation, auch eine stufenweise, immer bedeutet. Nicht nur, dass die konkrete sachliche Ausgestaltung einer Kodifikation höchst anspruchsvoll ist. Vor allem müssen in ihr die unterschiedlichsten (politischen) Interessen zum Ausgleich gebracht werden, damit die Kodifikation mehrheitsfähig ist. In diese ohnehin schon komplizierte Situation spielt, vermittelt über den Diskontinuitätsgrundsatz, der Faktor Zeit mit erheblichem Gewicht hinein. Kodifikationsgesetzgebung erstreckt sich regelmäßig über mehrere, nicht notwendig direkt aufeinander folgende, Legislaturperioden.

Wie bei jeder Gesetzgebung muss auch bei der Kodifikationsgesetzgebung der Entschluss zu ihr mit der Vergewisserung über die Kompetenzfrage (Art. 70 ff. GG) einhergehen. Das ist zwar eine Selbstverständlichkeit, verdient angesichts des übergreifenden Regelungsanspruchs von Kodifikationen und dem föderalen Kompetenzgeflecht der Bundesrepublik Deutschland allerdings verstärkte Beachtung. Der Kodifikationsgedanke bietet keine Möglichkeit, die föderale Kompetenzordnung zu überspielen. ${ }^{72}$ Eine unklare Kompetenz zum Gesetzeserlass hindert zwar nicht die Vorarbeiten zu einer Kodifikation. Spätestens vor Einleitung des Gesetzgebungsverfahrens muss die Kompetenzfrage allerdings geklärt sein, entweder im Wege der Auslegung oder durch Verfassungsänderung, wie das Beispiel UGB zeigt. ${ }^{73}$ Ein kompetenzwidriger Erlass, wie er mit dem Staatshaftungsgesetz vom 26. 06. $1981^{74}$ geschah, ${ }^{75}$ nachdem die ursprünglich geplante Grundgesetzänderung zur Einführung einer entsprechenden Kompetenzzuweisung scheiterte, ${ }^{76}$ ist keine Option. Mangelt es an einer (ausschließlichen) Bundeskompetenz, kommt ein mehr oder weniger abgestimmtes Vorgehen von Bund und Ländern wie bei den (L)VwVfGen (Simultangesetzgebung) ${ }^{77}$ oder der Länder untereinander, etwa über Musterentwürfe wie im

70 Burgi, Regulierungsverwaltung (Fn. 46), S. 2442.

$71 \mathrm{Zu}$ dieser allgemein W. Kahl/P. Hilbert, Folgenabschätzung als Instrument der Umwelt- und Technikgesetzgebung - Stand und Perspektiven, JbUTR 2009, S. $207 \mathrm{ff}$.

72 Vgl. Kabl, Kodifikationsidee (Fn. 8), S. 100 f.

73 Siehe oben Fn. 68.

74 BGBl. I, S. 553.

75 BVerfGE 61, 149. Art. 74 Abs. 1 Nr. 25 GG wurde erst mit Wirkung zum 15.11.1994 eingefügt.

76 Vgl. F. Ossenbühl, Anmerkung zu BVerfG, Urteil vom 19.10.1982 - 2 BvF 1/81 -, DÖV 1982, S. 987 (988).

77 Hierzu unten F. IV. 
allgemeinen Polizei- und Ordnungsrecht ${ }^{78}$ oder im Bauordnungsrecht, ${ }^{79}$ in Betracht. In diesen Fällen sind allerdings beträchtliche politische Vorarbeiten vonnöten und es wird erheblicher Abstimmungsbedarf erzeugt.

\section{Die Rolle der Wissenschaft}

Kodifikationen sind aus der Perspektive der Verwaltungsrechtswissenschaft zwar primär Projekte des Gesetzgebers. Gleichwohl hat hierbei auch die wissenschaftliche (Vor-)Arbeit Bedeutung. Das darf selbstverständlich nicht dahin missverstanden werden, dass der Rechtswissenschaft rechtserzeugende Kraft beigemessen würde. ${ }^{80}$ Die Verwaltungsrechtswissenschaft spielt aber durch ihre dogmatischen und gesetzgebungswissenschaftlichen Arbeiten bei der Entstehung von Kodifikationen eine eigenständige und keineswegs gering zu schätzende Rolle.

Eine Aufgabe der Verwaltungsrechtswissenschaft ist die Arbeit an einem wissenschaftlichen Allgemeinen Teil des Verwaltungsrechts, sprich an einem sich fortwährend überprüfenden und aktualisierenden Bestand von Lehren des Allgemeinen Verwaltungsrechts, die Ergebnis eines durch Europäisierung und Konstitutionalisierung mitgesteuerten wissenschaftlichen Auswahl- und Vermittlungsprozesses zwischen Besonderem und Allgemeinem Verwaltungsrecht sind. ${ }^{81}$ Dieser wissenschaftliche Allgemeine Teil ist $\mathrm{zu}$ unterscheiden von einem kodifizierten Allgemeinen Teil, wenngleich sich beide in ihrer Strukturierungsleistung und ihrer Verknüpfung von Besonderem und Allgemeinem ähneln und dabei auch Berührungspunkte aufweisen können. ${ }^{82}$ Der wissenschaftliche Allgemeine Teil ist ein Wissensbestand und als solcher kann er bei der Kodifikationsgebung genutzt werden. Wie bereits betont, setzt jede Kodifikation eine Systematisierung des Rechtsstoffs voraus. ${ }^{83}$ Diese wird durch

78 Vgl. W.-R. Schenke, Polizei- und Ordnungsrecht, 7. Aufl., Heidelberg u.a. 2011, Rn. 23 f., Anhang.

79 Vgl. H. Jäde, Grundlinien der Musterbauordnung 2002, ZfBR 2003, S. 221 ff.

80 Prononciert M. Jestaedt, Die Verfassung hinter der Verfassung, Paderborn u.a. 2009, S. 22 f.: „Wissenschaft schafft Wissen, nicht Recht.“ (S. 23).

81 E. Schmidt-Aßmann, Zur Funktion des Allgemeinen Verwaltungsrechts, Die Verwaltung 27 (1994), S. 137 ff.; ders., Das allgemeine Verwaltungsrecht als Ordnungsidee, 2. Aufl., Berlin, Heidelberg 2006, 1. Kap. Rn. 1-32; T. Groß, Die Beziehungen zwischen dem Allgemeinen und dem Besonderen Verwaltungsrecht, in: Die Wissenschaft vom Verwaltungsrecht, Die Verwaltung, Beiheft 2, Berlin 1999, S. 57 ff.; Kersten/Lenski, Entwicklungsfunktion (Fn. 29), S. 501 ff. Noch nicht abschließend geklärt ist, ob die Vermittlungs- und Entwicklungsbeziehungen zwischen Allgemeinem und Besonderem in direktem Austausch stattfinden (dafür Kersten/Lenski, a.a.O., S. 524-533) oder ob sie über eine dazwischen geschaltete Ebene mittlerer Abstraktionshöhe vermittelt werden (dafür R. Wahl, Die Aufgabenabhängigkeit von Verwaltung und Verwaltungsrecht, in: W. Hoffmann-Riem/E. Schmidt-Aßmann/G. F. Schuppert [Hrsg.], Reform des Allgemeinen Verwaltungsrechts, Baden-Baden 1993, S. 177 [209-216]). Zutreffend dürfte insoweit wohl eine vermittelnde Ansicht sein, die grundsätzlich beide Optionen anerkennt und dabei maßgeblich auf die Besonderheiten (Regelungsbreite und -tiefe, Homogenität/Heterogenität, Komplexität etc.) des jeweiligen Teilgebiets des Besonderen Verwaltungsrechts abstellt.

82 Groß, Beziehungen (Fn. 81), S. 70 f.; Kersten/Lenski, Entwicklungsfunktion (Fn. 29), S. 502 f., 532 ; Kahl, Entwicklung (Fn. 50), S. 137.

83 Siehe oben B. III. 
die wissenschaftliche Arbeit an den Lehren des Allgemeinen Verwaltungsrechts geleistet. Die Strukturierung des Rechtsstoffs erfolgt ausgehend vom geltenden Recht durch Rechtspraxis und Rechtswissenschaft sowie durch den ändernden Gesetzgeber selbst als fortlaufender Prozess und diskursive Aufgabe, ${ }^{84}$ deren Wahrnehmung wesentlich auf den „Prinzipien“ Kooperation und reziprokes Lernen beruht. Der so aggregierte Wissensbestand ist nicht nur ein Speicher für praktische Problemlösungen ${ }^{85}$ sondern auch ein Angebot an den Kodifikationsgesetzgeber, an dem er sich orientieren, ${ }^{86}$ das er aber auch ausschlagen kann. Kaum denkbar ist allerdings eine Gesetzgebung ohne Rückgriff auf jegliche wissenschaftliche Vorüberlegung, denn Parlament und Ministerialverwaltung haben schlicht nicht die personellen und zeitlichen Ressourcen zur Verfügung, den gesamten Rechtsstoff alleine aufzuarbeiten. Nicht vergessen werden darf in diesem Zusammenhang jedoch, dass Kodifikationsfragen immer auch Machtverteilungsfragen zwischen Rechtspraxis, Wissenschaft und Gesetzgeber sind, was jegliche Stellungnahmen zu ihnen, d.h. nicht nur die wissenschaftlicher Sachverständiger, beeinflussen kann. ${ }^{87}$

Ein weiterer Aspekt von Kodifikation als wissenschaftlichem Projekt ist, dass von Seiten der Wissenschaft aus vor der Folie der Allgemeinen Lehren rechtspolitische Kritik an etwaigen Kodifikationsentwürfen geübt werden kann. ${ }^{8}{ }^{8}$ Hierdurch können die politischen Entscheidungsträger zu Änderungen an den Gesetzesentwürfen motiviert werden. Jedenfalls aber kommt die Kritik der Kodifikation als Prozess ${ }^{89} \mathrm{zu}$ Gute. Eine Sonderform dieser Kritikfunktion ist die sachverständige Beratung während des Gesetzgebungsprozesses durch Wissenschaftler in besonderen Gremien oder öffentlichen Anhörungen.

\section{E. Kodifikationen im deutschen Verwaltungsrecht: Bestand und Bestrebungen}

Vor dem Hintergrund der allgemeinen Überlegungen zur Kodifikationsidee im Öffentlichen Recht soll ihre rechtsalltägliche Relevanz anhand einiger Beispiele veranschaulicht werden. Hierfür bietet sich ein Überblick über die bedeutsamsten bestehenden Kodifikationen und einige de lege ferenda diskutierten Kodifikationsbestre-

84 T.von Danwitz, Verwaltungsrechtliches System und Europäische Integration, Tübingen 1996, S. 41 f.; Schmidt-Aßmann, Ordnungsidee (Fn. 81), 7. Kap. Rn. 46; Kahl, Europäisierung (Fn. 4), S. 55 f.; vgl. auch H. Schulze-Fielitz, Notizen zur Rolle der Verwaltungsrechtswissenschaft für das Bundesverwaltungsgericht, Die Verwaltung 36 (2003), S. 421 (437-439).

85 Schmidt-Aßmann, Ordnungsidee (Fn. 81), 1. Kap. Rn. 4; H. Schulze-Fielitz, Verwaltungsrechtsdogmatik als Prozess der Ungleichzeitigkeit, Die Verwaltung 27 (1994), S. 277 (293).

86 von Danwitz, Verwaltungsrechtliches System (Fn. 84), S. 39; C. Starck, Rechtsdogmatik und Gesetzgebung im Verwaltungsrecht, in: O. Behrends/W. Henckel (Hrsg.), Gesetzgebung und Dogmatik, Göttingen 1989, S. 105 (108f.); O. Behrends, Das Bündnis zwischen Gesetz und Dogmatik und die Frage der dogmatischen Rangstufen, ebd., S. 9 (9).

87 Siehe am Beispiel des VwVfG A.-B. Kaiser, Die Kommunikation der Verwaltung, Baden-Baden 2009, S. 81 m. Nachw., vgl. auch S. 108 m. Fn. 197.

88 Schmidt-Aßmann, Funktion (Fn. 81), S. 141; Kahl, Europäisierung (Fn. 4), S. 47 f.

89 Siehe oben C. bei Fn. 37. 
bungen in den drei großen Blöcken des Verwaltungsrechts, dem Allgemeinem Verwaltungsrecht, dem Verwaltungsprozessrecht und dem Besonderen Verwaltungsrecht, an.

\section{Allgemeines Verwaltungsrecht}

Die wichtigste Kodifikation des Allgemeinen Verwaltungsrechts ist nach wie vor das VwVfG, ergänzt um die Verwaltungsverfahrensgesetze der Länder. ${ }^{90}$ Es handelt sich jeweils um Generalkodifikationen, die wiederum Teilkodifikationen (vgl. $\$ 1$ Abs. 1 a. E. VwVfG) sind..$^{91}$ Sie werden flankiert von den die Verwaltungszustellung und -vollstreckung regelnden Gesetzeswerken (VwZG, VwVG sowie ihre landesrechtlichen Pendants), die ebenfalls Generalkodifikationen sind, aber wegen der grundsätzlich abschließenden Normierung ihres Sachbereichs als Gesamtkodifikationen angesehen werden müssen. Die Verfahrensrechtsordnung des Verwaltungsrechts ist allerdings keine einheitliche. Neben die Verwaltungsverfahrensgesetze treten die Abgabenordnung (AO) und das SGB X. Sie sind eigenständige, sachbereichsspezifische Verfahrensordnungen und damit Bereichskodifikationen, ebenfalls in der Form von Teilkodifikationen. ${ }^{92}$ Aus der Perspektive einer allgemeinen Verfahrensrechtsordnung stellen sie sich als Sonderregelungen dar, das allgemeine Verwaltungsverfahrensrecht nimmt seinen Anwendungsbereich aber zu ihren Gunsten zurück ( $\$ 2$ Abs. 2 Nr. 1 und 4 VwVfG). Die Struktur des Verwaltungsverfahrensrechts ist somit von den drei Säulen VwVfG, AO, SGB X geprägt. ${ }^{93}$ Die dreiteilige Gliederung wird zumeist mit den Besonderheiten der Regelungsmaterien, die unterschiedliche Regelungsbedürfnisse nach sich zögen, gerechtfertigt. ${ }^{94}$ Rechtspolitisch bestand von Anfang an der Wunsch nach möglichst weitgehender Angleichung der drei Kodifikationen, ${ }^{95}$ was allerdings nicht immer gelingt. ${ }^{96}$

90 Zum Selbstverständnis des VwVfG als Kodifikation siehe BT-Drs. 7/910, S. 28. Überblick über die Landesverwaltungsverfahrensgesetze bei F. O. Kopp/U. Ramsauer, Verwaltungsverfahrensgesetz, 13. Aufl., München 2012, Einführung I Rn. 7 f.

$91 \mathrm{Kahl}$, Kodifikationsidee (Fn. 8), S. 84.

92 Für die AO J. Lang, in: K. Tipke/J. Lang, Steuerrecht, 20. Aufl., Köln 2010, $\$ 2$ Rn. 10-12.

93 Hierzu M. Sachs, in: P. Stelkens/H. J. Bonk/M. Sachs (Hrsg.), Verwaltungsverfahrensgesetz, 7. Aufl., München 2008, Einleitung Rn. 50-58.

94 BT-Drs. 7/910, S. 33, 34; BT-Drs. 7/4494, S. 3 f.; BT-Drs. 7/4292, S. 4 f.; BT-Drs. 8/2034, S. 29, 60; H. J. Bonk, 25 Jahre Verwaltungsverfahrensgesetz, NVwZ 2001, S. 636 (637); siehe auch K. A. Bettermann, Das Verwaltungsverfahren, VVDStRL 17 (1959), S. 118 (141-150, insb. S. 143, 149). Für ein einheitliches Verfahrensrecht hingegen P. Kirchhof, Bundessteuergesetzbuch, Heidelberg u.a. 2011, S. 340 f.; Peine, Entwicklung (Fn. 48), S. 2 f.; siehe auch Kopp/Ramsauer (Fn. 90), Einführung I Rn. 2 f.; $\$ 2$ Rn. 16.

95 Vgl. BT-Drs. 7/910, S. 107, 111; BT-Drs. 7/4494, S. 3 f.; sowie die Darstellung bei W. Klappstein, Rechtseinheit und Rechtsvielfalt im Verwaltungsrecht, Heidelberg 1994, S. 43-48 m. Nachw.

96 H.-G. Henneke/M. Ruffert, in: H. J. Knack/H.-G. Henneke (Hrsg.), Verwaltungsverfahrensgesetz, 9. Aufl., Köln 2010, Vor $\$ 1$ Rn. 8. 
Ebenfalls zum Allgemeinen Verwaltungsrecht zählt das öffentlich-rechtliche Informationsrecht. ${ }^{97}$ Es ist derzeit durch eine starke Rechtszersplitterung gekennzeichnet, ${ }^{98}$ weshalb es nicht verwundert, dass einige Stimmen in der Literatur für den Erlass einer gebietsübergreifenden Gesamtkodifikation in Form eines Informationsgesetzbuchs (IGB) plädieren. ${ }^{99}$ Gesetzgeberische Vorstöße sind insoweit allerdings nicht in Sicht. ${ }^{100}$ Gleiches gilt für die Kodifizierung des Staatshaftungsrechts. Die Forderung nach einem Staatshaftungsgesetz ist zwar unvermindert aktuell. ${ }^{101}$ Aller politischen Rhetorik zum Trotz werden legislative Bemühungen in diesem Bereich aber letztlich wohl zumindest einen unionsrechtlichen Anstoß brauchen.

\section{Verwaltungsprozessrecht}

Wie die Verwaltungsverfahrensrechtsordnung weist auch die Verwaltungsprozessrechtsordnung eine Drei-Säulen-Struktur auf. Neben die Generalkodifikation der Verwaltungsgerichtsordnung ( $\mathrm{Vw}_{w} \mathrm{GO}$ ) treten die Bereichskodifikationen der Finanzgerichtsordnung (FGO) und des Sozialgerichtsgesetzes (SGG). Alle drei Gesetzes-

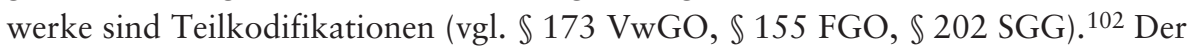
dreigeteilten Verfahrensrechtsordnung korrespondieren zudem drei institutionell verselbstständigte Gerichtsbarkeiten, die allgemeine Verwaltungsgerichtsbarkeit, die Finanzgerichtsbarkeit und die Sozialgerichtsbarkeit (vgl. Art. 95 Abs. 1 GG). Wegen der hier wie dort legislatorisch eingeführten Dreiteilung lassen sich die Verfahrensrechtsordnungen den Prozessrechtsordnungen zuordnen - ein Umstand, der - begrifflich verfehlt - als „Drei-Säulen-Theorie“ bezeichnet wird. ${ }^{103}$ Die Zuordnung darf nicht darüber hinwegtäuschen, dass keine Kongruenz zwischen den Anwendungsbereichen der Verfahrens- und Prozessrechtsordnungen besteht. Die Durch-

97 Vgl. R. Pitschas, Allgemeines Verwaltungsrecht als Teil der öffentlichen Informationsordnung, in: Hoffmann-Riem/Schmidt-Aßmann/Schuppert (Hrsg.), Reform (Fn. 81), S. 219 (241 f.); E. SchmidtAßmann, Zur Reform des Allgemeinen Verwaltungsrechts - Reformansätze und Reformbedarf, ebd., S. 11 (40); dens., Ordnungsidee (Fn. 81), 6. Kap. Rn. 3-11.

98 Siehe unten F. III.

99 M. Kloepfer, Informationsrecht, München 2002, $\mathbb{1}$ Rn. 93; G. Sydow, Informationsgesetzbuch häppchenweise, NVwZ 2008, S. 481 ff.; F. Schoch, Neuere Entwicklungen im Verbraucherinformationsrecht, NJW 2010, S. 2241 (2247). Siehe für Nordrhein-Westfalen auch den im Auftrag des Ministeriums für Inneres und Kommunales verfassten Entwurf eines einheitlichen Informationsgesetzes für Nordrhein-Westfalen von E. Beckmann/E. Sensburg/G. Warg, Die Zersplitterung der Informationsrechte als Chance für ein einheitliches Informationsgesetz?, VerwArch 103 (2012), S. $111 \mathrm{ff}$.

100 Die Bundesregierung sah zunächst keinen Bedarf für ein Informationsgesetzbuch (siehe BT-Drs. 16/8004, S. 5), zeigt sich im Anschluss an die Evaluierung des Verbraucherinformationsgesetzes (VIG) nun aber offener (vgl. BT-Drs. 17/1800, S. 7 f., 9 f.).

101 Siehe zuletzt den Bericht über das 13. Berliner Forum der Deutschen Gesellschaft für Gesetzgebung bei G. Krings/C.-H. Hentsch, Eckpunkte einer Kodifikation des Staatshaftungsrechts, ZG 2010, S. $205 \mathrm{ff}$.

102 Siehe für die VwGO E. Schmidt-Aßmann/W. Schenk, in: F. Schoch/J.-P. Schneider/W. Bier (Hrsg.), Verwaltungsgerichtsordnung, Bd. I, München, Loseblatt (Stand: 2012), Einleitung Rn. 94.

103 Vgl. C. H. Ule/H.-W. Laubinger, Verwaltungsverfahrensrecht, 4. Aufl., Köln u.a. 1995, $\$ 8$ Rn. 5. Die Bezeichnung Drei-Säulen-Theorie wird mittlerweile allerdings auch häufig zur Umschreibung der - begrifflich treffenderen - Drei-Säulen-Struktur des Verwaltungsverfahrensrechts gebraucht. 
führung eines Verwaltungsverfahrens nach einer Verfahrensrechtsordnung hat nicht zwingend die Einschlägigkeit der ihr zugeordneten Prozessrechtsordnung zur Folge. ${ }^{104}$ Die Verteilung der öffentlich-rechtlichen Streitigkeiten nichtverfassungsrechtlicher Art auf die unterschiedlichen Zweige der allgemeinen und besonderen Verwaltungsgerichtsbarkeit erfolgt durch ein diffiziles Regelungsgeflecht, das zudem von Zuweisungen an die ordentliche Gerichtsbarkeit durchzogen ist. ${ }^{105}$ Die Einheit der Kodifikation, insbesondere der VwGO, erodiert zudem durch die zunehmende Statuierung von „partikularem Sonderprozessrecht“, ${ }^{106}$ das sachbereichsspezifisch in den Fachgesetzen ${ }^{107}$ oder in eigenen Gesetzeswerken wie dem Umwelt-Rechtsbehelfsgesetz (UmwRG) bedeutsame Regelungen außerhalb der Kodifikation trifft. Auch die unterschiedlichen landesrechtlichen Ausgestaltungen der Notwendigkeit eines Vorverfahrens gem. $\$ 68$ VwGO als Sachentscheidungsvoraussetzung sind hier zu nennen. ${ }^{108}$

Als Reformperspektive wird beständig die Zusammenfassung der drei Prozessrechtsordnungen zu einer einheitlichen verwaltungsrechtlichen Prozessrechtskodifikation diskutiert. ${ }^{109}$ Obwohl diesbezüglich Entwürfe vorlagen, ${ }^{110}$ ist die Vereinheitlichung bis heute bloße Forderung geblieben. Noch weitergehend sind Reformvorschläge zur institutionellen Zusammenführung der drei Verwaltungsgerichtsbarkeiten, ${ }^{111}$ gleich $\mathrm{ob}$ in Kombination oder ohne Vereinheitlichung der Prozessrechtsordnungen. ${ }^{112}$

104 Sachs (Fn. 93), Einleitung Rn. 53.

105 Eingehend K. F. Gärditz, Die Rechtswegspaltung in öffentlich-rechtlichen Streitigkeiten nichtverfassungsrechtlicher Art, Die Verwaltung 43 (2010), S. 309 (310-325).

106 Gärditz, Rechtswegspaltung (Fn. 105), S. 333 f.

107 Ein wichtiges Beispiel ist das Verbandsklagerecht gem. $\int 64$ Bundesnaturschutzgesetz (BNatSchG). Ebenfalls bedeutsam sind die prozessualen Sonderregelungen im Asylrecht; vgl. hierzu K. F. Gärditz, Das Sonderverwaltungsprozessrecht des Asylverfahrens, in: P. Baumeister/W. Roth/J. Ruthig (Hrsg.), Staat, Verwaltung und Rechtsschutz. Festschrift für Wolf-Rüdiger Schenke zum 70. Geburtstag, Berlin 2011, S. 689 ff., insb. S. 699-706.

108 Zu diesen A. Glaser, in: K. F. Gärditz (Hrsg.), Verwaltungsgerichtsordnung, Köln u.a. i.E. (2012), \$68 Rn. 36-50.

109 Schmidt-Aßmann/Schenk (Fn. 102), Einleitung Rn. 98-99 a; J. Mayer-Ladewig, Aktualität einer Vereinheitlichung des Prozessrechts, NVwZ 2007, S. 1262 ff.; Gärditz, Rechtswegspaltung (Fn. 105), S. 337 f., 343-346.

110 C. H. Ule (Hrsg.), Entwurf eines Verwaltungsgerichtsgesetzes, Berlin 1969; Bundesministerium der Justiz (Hrsg.), Entwurf einer Verwaltungsprozeßordnung, Köln 1978; darauf aufbauend der von der damaligen Bundesregierung beschlossene Entwurf einer Verwaltungsprozeßordnung (VwPO), BTDrs. 9/1851 (vgl. dort, S. 60 f.).

111 Die Länder haben über den Bundesrat Gesetzesinitiativen in den Bundestag eingebracht, die ihnen die Zusammenführung der Verwaltungs-, Sozial- und Finanzgerichtsbarkeit ermöglichen sollten; vgl. BR-Drs. 543/04; BR-Drs. 544/04; BT-Drs. 15/4108; BT-Drs. 15/4109. Sie fielen der Diskontinuität anheim, wurden erneut eingebracht (BR-Drs. 46/06; BR-Drs. 47/06; BT-Drs. 16/1034; BT-Drs. 16/1040), aber nie beschlossen. Zu ihrem Inhalt siehe F. Wittreck, Auftakt zu einer neuen Runde: die Vereinheitlichung der öffentlich-rechtlichen Fachgerichtsbarkeiten, DVBl. 2005, S. $211 \mathrm{ff.}$

112 Wittreck, Vereinheitlichung (Fn. 111), S. 211 f.; Gärditz, Rechtswegspaltung (Fn. 105), S. 337-343; skeptisch zur Durchsetzbarkeit Meyer-Ladewig, Vereinheitlichung (Fn. 109), S. 1262 f., 1264 f.; F. Schoch, Gerichtliche Verwaltungskontrollen, in: W. Hoffmann-Riem/E. Schmidt-Aßmann/A. Voßkuhle (Hrsg.), Grundlagen des Verwaltungsrechts, Bd. III, München 2009, \$ 50 Rn. 102 f. 


\section{Besonderes Verwaltungsrecht}

Das Besondere Verwaltungsrecht setzt sich zusammen aus einer Vielzahl von Gesetzeswerken. Sie ist der Vielgestaltigkeit der Regelungsmaterien geschuldet. Eine übergreifende Generalkodifikation, wie sie im Allgemeinen Verwaltungsrecht vorstellbar wäre, ist deshalb unmöglich. Im Normbestand des Besonderen Verwaltungsrechts finden sich zwar auch Kodifikationen. Vor allem in den „klassischen“ Gebieten existieren in den Bundesländern Bereichskodifikationen, die oft vergleichbare Strukturen aufweisen, wie beispielsweise die Polizeigesetze ${ }^{113}$ oder die Gemeindeordnungen (bzw. ihre Äquivalente). ${ }^{114}$ Das Öffentliche Baurecht ist auf Länderebene von den Teilkodifikationen der Landesbauordnungen, auf Bundesebene vom Baugesetzbuch (BauGB) geprägt. Hier wird besonders deutlich, vor welche Herausforderungen die bundesstaatliche Kompetenzordnung die Kodifikationsidee im Verwaltungsrecht stellt. ${ }^{115}$ Da die Gesetzgebungskompetenz für das Bauplanungsrecht beim Bund (Art. 74 Abs. 1 Nr. 18 GG), die für das Bauordnungsrecht bei den Ländern (Art. 70 GG) liegt, ist eine baurechtliche Gesamtkodifikation nicht realisierbar. Gleichwohl hat sich auf Grundlage der bundes- und landesrechtlichen Teilkodifikationen ein einigermaßen einheitliches Baurecht ausgebildet. ${ }^{116}$

Geprägt ist das Besondere Verwaltungsrecht aber im Schwerpunkt von Einzelgesetzen. Diese wiederum stehen oftmals nicht beziehungslos nebeneinander. Überschneidungen der Regelungsbereiche kommen häufig vor. Zudem sind weite Teile des Besonderen Verwaltungsrechts vom Unionsrecht geprägt und mit ihm eng verzahnt. ${ }^{117}$ Darüber hinaus, teilweise aber auch deswegen, tritt in einigen Rechtsbereichen neben die gesetzlichen Regelungen eine erhebliche Anzahl von Rechtsverordnungen. ${ }^{118}$ Bereits diese sehr skizzenhafte Umschreibung reicht aus, um die Mosaikhaftigkeit des Besonderen Verwaltungsrechts anzudeuten. Fehlende materiellrechtliche Einheitlichkeit kann allerdings ein Stück weit auf Ebene des Vollzugs kompensiert werden, ${ }^{119}$ beispielsweise durch Anordnung der Konzentrationswir-

113 Vgl. C. Gusy, Polizei- und Ordnungsrecht, 8. Aufl., Tübingen 2011, Rn. 29 f.

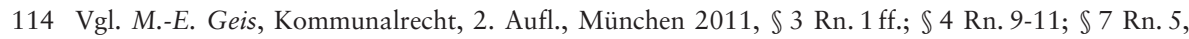
wobei hier Ausnahmen für die Kommunalgesetze der Stadtstaaten gelten.

115 Siehe oben D. I. 2.

116 Erst auf derartiger Grundlage sind länderübergreifende Lehrbuchdarstellungen möglich; siehe z.B. F. Stollmann, Öffentliches Baurecht, 8. Aufl., München 2011; W. Hoppe/C. Bönker/S. Grotefels, Öffentliches Baurecht, 4. Aufl., München 2010; H.-J. Koch/R. Hendler, Baurecht, Raumordnungsund Landesplanungsrecht, 5. Aufl., Stuttgart 2009. Zum Stand der Harmonisierung im Bauordnungsrecht vgl. W. Erbguth/F. Stollmann, Entwicklung im Bauordnungsrecht, JZ 2007, S. 868 (869-872).

117 Z.B. das Umweltrecht, das Lebensmittelrecht, das Arzneimittelrecht.

118 Z.B. im Immissionsschutzrecht, im Abfallrecht, im Energierecht.

119 Vgl. aber auch zum umgekehrten Phänomen der teilweisen Auflösung materiell-rechtlicher Einheitlichkeit aufgrund des Vollzugs durch unterschiedliche Vollzugsorgane Schulze-Fielitz, Einheitsbildung (Fn. 39), S. 141-146. 
kung behördlicher Entscheidungen, wie in $\$ 13 \mathrm{BImSchG,} \mathrm{wenngleich} \mathrm{hiermit} \mathrm{neue}$ Probleme verbunden sind. ${ }^{120}$

Nichtsdestotrotz bleibt die Schaffung von Kodifikationen im Besonderen Verwaltungsrecht möglich. Das SGB zeigt, dass selbst ausgreifende Regelungsmaterien sukzessive legislativ zusammengeführt werden können. ${ }^{121}$ Mit seinem Büchersystem war es zudem Vorbild für das Projekt eines UGB, ${ }^{122} \mathrm{dem}$ Kodifikationsvorhaben des Öffentlichen Rechts der letzten 20 Jahre. ${ }^{123}$ Nach dessen letztem Scheitern im Jahr 2009, das einmal mehr die Unwägbarkeiten und die „Irrationalität“ von Gesetzgebungsprozessen vor Augen geführt hat, ${ }^{124}$ sind zwar mit dem Bundesnaturschutzgesetz (BNatSchG), dem Wasserhaushaltsgesetz (WHG) und dem Gesetz zum Schutz vor nichtionisierender Strahlung bei der Anwendung am Menschen (NiSG), Teile der geplanten Kodifikation (sogenannte „kleine Lösung“) gesondert verabschiedet worden. Die Forderung nach einer Kodifikation in Gestalt eines UGB hat indes nichts an Aktualität eingebüßt, ${ }^{125}$ zumal das Umweltrecht trotz unterschiedlicher Regelungsfelder und erheblicher unionsrechtlicher Vorprägung einen hohen Grad an wissenschaftlicher Durchdringung und Systematisierung aufweist. Die für das Umweltrecht

120 Siehe F. Wittreck, Konzentration als Verfahrenshemmnis?, VerwArch 100 (2009), S. 71 ff., insb. S. 81-94; ferner A. Berger, Rechtliche Ordnung paralleler Anlagenkontrollverfahren, VerwArch 100 (2009), S. 342 ff. Die Anordnung einer (formellen) Konzentrationswirkung darf indes nicht gleichgesetzt werden mit der im UGB I vorgesehenen integrierten Vorhabengenehmigung, durch die auch materiell ein einheitliches Prüf- und Entscheidungsprogramm geschaffen worden wäre, siehe W. Kabl/ $B$. Welke, Über die unveränderte Notwendigkeit einer integrierten Vorhabengenehmigung und deren Regelungsstandort, DVBl. 2010, S. 1414 (1415 f.).

121 C. Waibel, Fortschreiten der Kodifikation des SGB: Begründung eines geschlossenen Systems?, ZfS 2004, S. 341 ff.; E. Eichenhofer, Sozialrecht, 8. Aufl., Tübingen 2012, Rn.167-170. Kritisch T. Ramm, Von der Arbeiterversicherung zum Sozialgesetzbuch, Jahrbuch der Juristischen Zeitgeschichte 9 (2007/2008), S. 87 (107-110): „Scheinkodifikation“ (S. 109).

122 A. Guckelberger, Der Referentenentwurf für ein UGB 2009 als erster Schritt auf dem Weg zur Kodifikation des Umweltrechts, NVwZ 2008, S. 1161 (1163). Siehe zu dieser Regelungstechnik am Beispiel des SGB und des UGB F. Schärdel, Die Bücherkodifikation. Untersuchung einer Gesetzgebungstechnik, Baden-Baden 2012, insb. S. 133-227.

123 Siehe nur M. Kloepfer, Das Umweltgesetzbuch auf dem Weg. Zum Referentenentwurf eines UGB (UGB-RefE), Die Verwaltung 41 (2008), S. 195 ff.; C. Sangenstedt, Der Referentenentwurf für ein Umweltgesetzbuch, in: W. Köck (Hrsg.), Auf dem Weg zu einem Umweltgesetzbuch nach der Föderalismusreform, Baden-Baden 2009, S. 25 ff. Überblick über die Historie der Kodifikationsbestrebungen bei R. Schmidt/W. Kahl, Umweltrecht, 8. Aufl., München 2010, $\$ 1$ Rn. 4-15. Zu den Vorund Nachteilen einer Kodifikation des Umweltrechts in einem UGB Debus, Kodifikation (Fn. 47), S. $21 \mathrm{ff}$.

$124 \mathrm{Zu}$ den - aus juristischer Sicht nicht überzeugenden, letztlich in starkem Maße sachfremden (insbesondere parteipolitischen und wahlstrategischen) - Gründen („Monsterbürokratie“ etc.), die am Ende zum Scheitern des (bislang) letzten Anlaufs zur Schaffung eines UGB (vgl. den Entwurf in der Fassung vom Dezember 2008, abrufbar unter: http://www.bmu.de/gesetze_verordnungen/bmudownloads/doc/40448.php [letzter Aufruf: 30.10.2012]) geführt haben, eingehend Kabl/Welke, Vorhabengenehmigung (Fn. 120), S. 1414 ff.; B. Welke, Die integrierte Vorhabengenehmigung, Tübingen 2010, S. 325-350, 367-370.

125 A. Scheidler, Die anstehende Neuordnung des Umweltrechts nach dem Scheitern des Umweltgesetzbuchs, UPR 2009, S. 173 (176); Schmidt/Kahl, Umweltrecht (Fn. 123), \$1 Rn. 14; M. Kloepfer, Umweltschutzrecht, 2. Aufl., München 2011, $\mathbb{1}$ Rn. 55; Welke, Vorhabengenehmigung (Fn. 124), S. 371-378, 385-387; a.A. B. Weber/D. Riedel, Brauchen wir das Umweltgesetzbuch noch? Wider die Legendenbildung über das gescheiterte UGB, NVwZ 2009, S. 998 ff. 
aufrechtzuerhaltende Forderung nach einer Kodifikation kann hingegen für das Wirtschaftsverwaltungsrechts nicht formuliert werden, da dieses $\mathrm{zu}$ heterogen ist. ${ }^{126}$ Möglich wäre jedoch eine im Schrifttum bereits verschiedentlich vorgeschlagene Rekodifikation des Gewerberechts; ${ }^{127}$ ein Entwurf eines Allgemeinen Teils des Gewerberechts wurde hierzu vorgelegt. ${ }^{128}$ Kontrovers diskutiert wird zudem die „Normierung eines ,Allgemeinen Teils' des Netzregulierungsrechts" 129 durch eine sektorenübergreifende Teilkodifikation des Regulierungsrechts der Netzwirtschaften (Energie, Telekommunikation, Post und Bahn). ${ }^{130} \mathrm{Im}$ als Paradebeispiel legislativer Unübersichtlichkeit geltenden Steuerrecht hat der groß angelegte Reformvorschlag der Kodifikation eines Bundessteuergesetzbuchs Aufmerksamkeit erfahren. ${ }^{131}$ Insgesamt kann jedoch festgehalten werden, dass die Kodifikationsidee im Allgemeinen Verwaltungsrecht und im Verwaltungsprozessrecht stärkere Wirkkraft zu entfalten vermag, als im notwendigerweise buntscheckigen Besonderen Verwaltungsrecht.

\section{F. Das VwVfG als Kodifikation}

\section{Allgemeines}

Besondere Aufmerksamkeit verdient das VwVfG als die zentrale Kodifikation des Verwaltungsrechts. Das Vorhaben einer Kodifizierung von Fragen des Allgemeinen Verwaltungsrechts, insbesondere des Verwaltungsverfahrensrechts, zumal auf Bundesebene, war in der jungen Bundesrepublik zwar nicht unumstritten. ${ }^{132}$ Die Beden-

126 Kahl, Kodifikationsidee (Fn. 8), S. 107 f.; R. Stober, Allgemeines Wirtschaftsverwaltungsrecht, 17. Aufl., Stuttgart 2011, S. 16; R. Schmidt, Öffentliches Wirtschaftsrecht. Allgemeiner Teil, Berlin u.a. 1990 , S. 52-55, $58 \mathrm{f}$.

127 Vgl. Peine, Kodifikationsidee (Fn. 9), S. 672-676, 679-685, 687 f. Überblick über die Reformdiskussion bei R. Stober/S. Eisenmenger, Besonderes Wirtschaftsverwaltungsrecht, 15. Aufl., Stuttgart 2011, S. 6-11.

128 R. Stober, Gewerbeordnung 21, Diskussionsentwurf eines Allgemeinen Teils einer Gewerbeordnung für das 21. Jahrhundert, NVwZ 2003, S. $1349 \mathrm{ff}$.

129 J. Masing, Soll das Recht der Regulierungsverwaltung übergreifend geregelt werden? Gutachten D für den 66. Deutschen Juristentag, in: Ständige Deputation des Deutschen Juristentages (Hrsg.), Verhandlungen des 66. Deutschen Juristentages, Bd. I, München 2006, S. D 102, siehe auch S. D 10, D 192.

130 Masing, Regulierungsverwaltung (Fn. 129); vgl. auch H. C. Röhl, Soll das Recht der Regulierungsverwaltung übergreifend geregelt werden?, JZ 2006, S. $831 \mathrm{ff}$.; ablehnend Burgi, Regulierungsverwaltung (Fn. 46), S. 2439 ff.; S. Storr, Soll das Recht der Regulierungsverwaltung übergreifend geregelt werden?, DVBl. 2006, S. $1017 \mathrm{ff}$.; W. Kahl, Über einige Pfade und Tendenzen in Verwaltungsrecht und Verwaltungsrechtswissenschaft - ein Zwischenbericht, Die Verwaltung 42 (2009), S. 463 (484f.).

131 Kirchhof, Bundessteuergesetzbuch (Fn. 94).

132 Zeitgenössische Kritik etwa bei M. Baring, Bloß kein Gesetz!, JR 1960, S. 241 ff.; F. Werner, Empfiehlt es sich, den allgemeinen Teil des Verwaltungsrechts zu kodifizieren? Gutachten für den 43. Deutschen Juristentag, in: Ständige Deputation des Deutschen Juristentages (Hrsg.), Verhandlungen des 43. Deutschen Juristentages, Bd. I 2. Teil B, Tübingen 1960, S. 21-40, insb. S. 34-37. Die zweite Abteilung des 43. Deutschen Juristentages hat hingegen beschlossen, sich für eine Kodifikation auszusprechen; vgl. Ständige Deputation des Deutschen Juristentages (Hrsg.), Verhandlungen des 43. Deutschen Juristentages, Bd. II, Tübingen 1962, S. D 149. 
ken konnten sich in dem gut zwei Jahrzehnte ${ }^{133}$ dauernden Entstehungsprozess aber zu Recht nicht durchsetzen, ${ }^{134}$ so dass am 01. 01. 1977 das VwVfG in Kraft treten konnte. ${ }^{135}$ Seitdem hat sich das VwVfG bewährt. ${ }^{136}$ Grundsätzliche Kritik wird, soweit ersichtlich, nicht erhoben. Gleichwohl bestand und besteht hinsichtlich der Kodifikation(en) des Verwaltungsverfahrensrechts fortdauernder Diskussionsbedarf, der auch publizistische Spuren hinterlässt. ${ }^{137}$ Der Reformbedarf muss vor dem Hintergrund der Stärken und Schwächen des VwVfG immer wieder ausgelotet werden.

\section{Stärken}

Die Stärken des VwVfG decken sich nahezu vollständig mit den generellen Vorteilen einer Kodifikation. ${ }^{138}$ Insbesondere die mit seinem Erlass verfolgten Zielsetzungen, ${ }^{139}$ über die bundesweite Rechtsvereinheitlichung die Tätigkeit der Verwaltungsbehörden und der Gerichte zu vereinfachen und für den Bürger mehr Transparenz und Rechtssicherheit herzustellen, wurden erreicht. ${ }^{140}$ Eine Schlüsselrolle kommt hierbei der Modellfunktion zu, die das VwVfG in den von ihm geregelten Bereichen entfalten kann. ${ }^{141}$ Die angesichts der Vielzahl von Akteuren im Bereich der Verwal-

133 Als zeitliche Orientierungsposten mögen die Einberufung einer Sachverständigenkommission für die Vereinfachung der Verwaltung im Jahr 1957 (deren Ergebnisse zusammengefasst sind im Bericht der Sachverständigenkommission für die Vereinfachung der Verwaltung beim Bundesministerium des Innern, Bonn 1960. Zur Kodifikationsfrage siehe insb. S. 33, 55-65) und das Inkrafttreten des VwVfG am 1.1.1977 (BGBl. 1976 I, S. 1253) dienen.

134 M. Thiel, Die Verwaltungsverfahrensgesetze des Bundes und der Länder - Gelungene Kodifikationen oder geduldete Regelwerke? -, Ad Legendum 2011, S. 93 (94 f.).

135 Siehe zum Kodifizierungsprozess des VwVfG statt vieler Kaiser, Kommunikation (Fn. 87), S. 73-87, 101-106; C. H. Ule, Die Kodifizierung des Verwaltungsverfahrensrechts, in: K. G. A. Jeserich/H. Pohl/G.-C. von Unruh (Hrsg.), Deutsche Verwaltungsgeschichte, Bd. V, Stuttgart 1987, S. 1162 ff.; W. Klappstein, Rechtseinheit (Fn. 95), S. 14-43; bündige Übersicht bei J.-P. Schneider, Strukturen und Typen von Verwaltungsverfahren, in: W. Hoffmann-Riem/E. Schmidt-Aßmann/A. Voßkuhle (Hrsg.), Grundlagen des Verwaltungsrechts, Bd. II, 2. Aufl., München 2012, $\$ 28$ Rn. 9.

136 Es hat zudem vergleichsweise wenige Änderungen erfahren; siehe insoweit den Überblick bei Kopp/ Ramsauer (Fn. 90), Einführung I Rn. 29-35 c.

137 Genannt seien nur die wichtigen Sammelbände W. Blümel (Hrsg.), Vereinheitlichung (Fn. 7); W. Blümel/R. Pitschas (Hrsg.), Reform des Verfahrensrechts, Berlin 1994; W. Hoffmann-Riem/E. Schmidt-Aßmann (Hrsg.), Verwaltungsverfahren (Fn. 8); M. Burgi/K. Schönenbroicher (Hrsg.), Die Zukunft des Verwaltungsverfahrensrechts, Baden-Baden 2010; H. Hill/K.-P. Sommermann/U. Stelkens/J. Ziekow (Hrsg.), 35 Jahre (Fn. 34).

$138 \mathrm{Zu}$ diesen oben C. m. Fn. 31. Abschläge in dieser Bilanz müssen jedoch für die Rezeptionsleitungsfunktion (zu dieser Kahl, Kodifikationsidee [Fn. 8], S. 97), gerade in Hinblick auf die Rezeption unionsrechtlicher Vorgaben, konstatiert werden, vgl. unten F. III.

139 Vgl. BT-Drs. 7/910, S. $28 \mathrm{f}$.

140 Ule/Laubinger, Verwaltungsverfahrensrecht (Fn. 103), $\$ 5$ Rn. 1-5; M. Burgi/W. Durner, Modernisierung des Verwaltungsverfahrensrechts durch Stärkung des VwVfG, Baden-Baden 2012, S. $19 \mathrm{f}$.

141 J. Ziekow, Governance des Verwaltungsverfahrens als Aufgabe des Verwaltungsverfahrensrechts, in: Hill et al. (Hrsg.), 35 Jahre (Fn. 34), S. 95 (101-103); Kahl, Kodifikationsidee (Fn. 8), S. 92 f., 94 f. 
tungsverfahrensgesetzgebung ${ }^{142}$ stets mögliche Rechtszersplitterung kann eingedämmt werden, wenn das VwVfG überzeugende Regelungsmodelle anbietet (Angebotsgesetzgebung), ${ }^{143}$ die andere Rechtsetzer aufgreifen können. Zwar hat das VwVfG nie eine Vereinheitlichung des gesamten Verwaltungsverfahrensrechts bewirken wollen und weitere Erosionen der Rechtseinheit im Verwaltungsverfahrensrecht sind zu beobachten. ${ }^{144}$ Allerdings hat das VwVfG bewiesen, dass es über seine Modellfunktion zur Rechtsvereinheitlichung - und damit aller mit ihr verbundenen Vorteile - beitragen kann. Hierin liegt seine wesentliche Stärke.

\section{Schwächen}

Das VwVfG weist aus heutiger Sicht ${ }^{145}$ aber auch konzeptionelle Schwächen auf. ${ }^{146}$ Sie liegen vor allem in seiner zu einseitigen Fixierung auf den Einzelfall gestaltende Entscheidungen ( $\$ 9 \mathrm{VwVfG}$ ) unter Beschränkung auf die Erscheinungsformen des Verwaltungsakts ( $\mathbb{S} 35 \mathrm{ff}$. VwVfG) und des öffentlich-rechtlichen Vertrags ( $\mathbb{\$} 54 \mathrm{ff}$. VwVfG). Demgegenüber wird die administrative Handlungspraxis längst in einer größeren Vielfalt wahrgenommen. ${ }^{147}$ Von daher erscheinen fehlende Regelungen zur exekutiven Rechtsetzung durch Rechtsverordnung, Satzung und Verwaltungsvorschrift, ${ }^{148}$ dem Handeln in Privatrechtsform ${ }^{149}$ sowie verwaltungsbehördlichen Realakten, ${ }^{150}$ d.h. schlichtem und informellem Verwaltungshan-

142 In vertikaler Hinsicht verteilen sich die Gesetzgebungskompetenzen auf den Bund und die 16 Länder; in horizontaler Hinsicht sind für das oftmals auf Verfahrensfragen ausgreifende Fachrecht unterschiedliche Ressorts zuständig, was zu sachbereichsspezifischen Sonderregelungen führen kann. Hinzu kommen Beeinflussungen von außerhalb des Parlaments und der Ministerialbürokratie stehenden Akteuren (z.B. Verbände); vgl. hierzu Schuppert, Rechtsetzung (Fn. 39), S. 44-55, 72-79.

143 R. Wahl, Fehlende Kodifizierung der förmlichen Genehmigungsverfahren im Verwaltungsverfahrensgesetz, NVwZ 2002, S. 1192 (1194).

144 Siehe unten F. III.

145 Bei seinem Erlass war die Beschränkung des Regelungsumfangs aufgrund noch nicht hinreichend fortgeschrittener wissenschaftlicher Durchdringung der im Folgenden erwähnten Bereiche durchaus nachvollziehbar.

146 E. Schmidt-Aßmann, Der Verfahrensgedanke im deutschen und europäischen Verwaltungsrecht, in: Hoffmann-Riem/Schmidt-Aßmann/Voßkuhle (Hrsg.), Grundlagen (Fn. 135), \$27 Rn. 12-14; Schneider, Strukturen und Typen (Fn. 135), $\$ 28$ Rn. $12 \mathrm{f}$.

147 Schmidt-Aßmann, Ordnungsidee (Fn. 81), 6. Kap. Rn. 1.

148 M. Möstl, Normative Handlungsformen, in: H.-U. Erichsen/D. Ehlers (Hrsg.), Allgemeines Verwaltungsrecht, 14. Aufl., Berlin, New York 2010, \$19 Rn.15-17; Hoffmann-Riem, Verwaltungsverfahren (Fn. 34), S. 51 f.; zum Ganzen, allerdings für bereichsspezifische Lösungen plädierend, H. Hill/ M. Martini, Normsetzung und andere Formen exekutivischer Selbstprogrammierung, in: HoffmannRiem/Schmidt-Aßmann/Voßkuhle (Hrsg.), Grundlagen (Fn. 135), \34 Rn. 15-17 m. Nachw.

149 Vgl. zur Problematik W. Kahl, Privatrechtliches Verwaltungshandeln und Verwaltungsverfahrensgesetz am Beispiel des Vergaberechts, in: M. Aschke/F. Hase/R. Schmidt-De Caluwe (Hrsg.), Selbstbestimmung und Gemeinwohl. Festschrift für Friedrich von Zezschwitz zum 70. Geburtstag, BadenBaden 2005, S. $151 \mathrm{ff}$.

150 Überblick bei W. Hoffmann-Riem, Rechtsformen, Handlungsformen, Bewirkungsformen, in: ders./ Schmidt-Aßmann/Voßkuhle (Hrsg.), Grundlagen (Fn. 135), $\$ 33$ Rn. 34. 
deln, ${ }^{151}$ als Desiderat, ${ }^{152}$ wenngleich nicht alle Erscheinungsformen administrativen Handelns (vorschnell) im VwVfG normiert werden können und sollen. ${ }^{153}$ Das Fehlen einer allgemeinen rechtlichen Einhegung des durch gleich bleibend hohe Aktualität und hinreichende wissenschaftliche Durchdringung gekennzeichneten staatlichen Informationshandelns ${ }^{154}$ im VwVfG sticht - nicht zuletzt wegen seiner Grundrechtsrelevanz im negativen (Eingriff) wie im positiven (milderes Mittel) - allerdings stark ins Auge. ${ }^{155}$ Hinzu kommt eine für ein Verwaltungsverfahrensgesetz erstaunliche Zurückhaltung bei der Normierung von Verfahrenstypen. Neben allgemeinen Regelungen zum im Grundsatz nicht förmlichen Verwaltungsverfahren $(\mathbb{S} \mathbb{S} 9 \mathrm{ff}$. $\mathrm{VwVfG}$ ) treten Bestimmungen über das förmliche Verwaltungsverfahren $(\mathbb{S} \mathbb{S} 63 \mathrm{ff}$. $\mathrm{VwVfG}$ ), das Verfahren über eine einheitliche Stelle ( $\mathbb{\$} \$ 71 \mathrm{aff}$. VwVfG) und das Planfeststellungsverfahren ( $\mathbb{S} 72 \mathrm{ff}$. VwVfG). Da das Verfahren über die einheitliche Stelle vor allem der Koordinierung mehrerer nebeneinander durchzuführender Verwaltungsverfahren dient, bei der die einheitliche Stelle zur Umsetzung des One-StopShop-Ansatzes vor allem als Verfahrensmittlerin auftritt, ${ }^{156}$ und die Vorschriften über das förmliche Verwaltungsverfahren praktisch weitgehend bedeutungslos geblieben sind, ${ }^{157}$ entfaltet das VwVfG, genau genommen, Prägekraft nur für zwei selbstständige Verfahrenstypen. Dass diese für die funktionsgerechte Tätigkeit der Exekutive in einem modernen Staat nicht ausreichen, versteht sich von selbst und findet seinen Niederschlag in unterschiedlichen fachgesetzlichen Verfahrensregelungen und der auf sie aufbauenden Systematisierung verschiedener Verfahrenstypen

151 Zur Abgrenzung siehe M. Fehling, Informelles Verwaltungshandeln, in: Hoffmann-Riem/SchmidtAßmann/Voßkuhle (Hrsg.), Grundlagen (Fn. 135), \38 Rn. 14-16; G. Hermes, Schlichtes Verwaltungshandeln, ebd., $\mathbb{S} 39 \mathrm{Rn} .30 \mathrm{f}$.

152 F. Hufen, Das VwVfG nach 30 Jahren: Wahrgenommene Chance - Hürde - Meilenstein?, in: D. Heckmann (Hrsg.), Modernisierung von Justiz und Verwaltung. Gedenkschrift für Ferdinand O. Kopp, Stuttgart u.a. 2007, S. 38 (42-45); H. Pünder, Verwaltungsverfahren, in: Erichsen/Ehlers (Hrsg.), Allgemeines Verwaltungsrecht (Fn. 148), $\mathbb{1 3}$ Rn. 6.

153 Vgl. E. Schmidt-Aßmann, Ordnungsidee und Steuerungsfunktion des Allgemeinen Verwaltungsrechts, in: W. Spannowsky (Hrsg.), Erscheinungsbilder eines sich wandelnden Verwaltungsrechts. Günter Püttner zum 70. Geburtstag, Köln u.a. 2006, S. 3 (3-7).

154 Siehe statt vieler C. Bumke, Publikumsinformation, Die Verwaltung 37 (2004), S. 3 ff.; C. Gusy, Die Informationsbeziehungen zwischen Staat und Bürger, in: Hoffmann-Riem/Schmidt-Aßmann/ Voßkuhle (Hrsg.), Grundlagen (Fn. 135), \$23 Rn.95-111; F. Schoch, Die Schwierigkeiten des BVerfG mit der Bewältigung staatlichen Informationshandelns, NVwZ 2011, S. 193 ff.

155 Nicht überzeugend ist die These des BVerfG (E 105, 279 [304 f.]), gubernatives Informationshandeln lasse sich gesetzlich nicht sinnvoll normieren. Hierzu J. H. Klement, Der Vorbehalt des Gesetzes für das Unvorhersehbare - Argumente gegen zu viel Rücksicht auf den Gesetzgeber -, DÖV 2005, S. $507 \mathrm{ff}$.

156 Schmitz/Prell, Verfahren über eine einheitliche Stelle (Fn. 50), S. 4 f.

157 R. Wahl, Neues Verfahrensrecht für Planfeststellung und Anlagengenehmigung - Vereinheitlichung des Verwaltungsverfahrens oder bereichsspezifische Sonderordnung?, in: Blümel/Pitschas (Hrsg.), Reform (Fn. 137), S. 83 (91-93); A. Metschke, Wahrnehmung und Bedeutung des Verwaltungsverfahrensrechts aus der Sicht des Anwenders: Verwaltung, in: Hill et al. (Hrsg.), 35 Jahre (Fn. 34), S. 55 (62). 
(z.B. Verteilungsverfahren, Qualitätssicherungsverfahren, Risikoverfahren). ${ }^{158}$ Das heißt freilich nicht, dass im VwVfG alle oder auch nur einige der neuen Verfahrenstypen kodifiziert werden sollten; ${ }^{159}$ Kodifikationsfähigkeit und Kodifikationsbedürftigkeit müssen stets gesondert und sorgfältig ermittelt werden. Bemerkbar macht sich die zurückhaltende Verfahrensnormierung aber bei der fehlenden Kodifizierung eines förmlichen Genehmigungsverfahrens, das als ausreichend durchdrungener Verfahrensgrundtyp einer Aufnahme in das VwVfG bedarf. ${ }^{160}$ Ein weiterer Makel ist das derzeitige weitgehende - eine Ausnahme bilden die Vorschriften zur Verwaltungszusammenarbeit im Binnenmarkt $(\mathbb{S} \mathbb{S} 8 \text { aff. } V w V f G)^{161}$ - Schweigen des VwVfG zur Internationalisierung und insbesondere zur Europäisierung des Verwaltungsrechts. Das Auseinanderklaffen von Normtext und Rechtspraxis bei der Aufhebung von Verwaltungsakten gem. $\int \mathbb{S} 48 \mathrm{f}$. VwVfG in unionsrechtlich determinierten Fällen ${ }^{162}$ ist nur das augenfälligste Beispiel dafür, dass ein national introvertiertes VwVfG den heutigen Regelungsbedürfnissen nicht mehr gerecht wird. Gerade in Hinblick auf die Kooperation im europäischen Verwaltungsverbund ist eine Weiterentwicklung der Kodifikation von Nöten. ${ }^{163}$ Dass der Gesetzgeber des VwVfG auf unionsrechtlichen Anpassungsdruck auf souveräne Weise systembildend reagieren kann, hat er mit der Umsetzung der EU-Dienstleistungsrichtlinie unter Beweis gestellt. ${ }^{164}$

Als weitere Schwäche des VwVfG ist sein beschränkter Anwendungsbereich $(\mathbb{S} 1 \mathrm{f}$. $\mathrm{VwVfG})$ zu verbuchen. Die bundesstaatlich vertikale Zurücknahme $(\mathbb{S} 1 \mathrm{Abs.} 3$ VwVfG) zu Gunsten der Landesgesetzgebung ist zwar aus Kompetenzgründen unvermeidbar. ${ }^{165}$ Schwerer wiegt aber ohnehin die horizontale Zurücknahme $(\mathbb{S} 1$ Abs. 1 a. E., $\mathbb{S} 2$ VwVfG). Auf ihrer Grundlage ist zum einen die Drei-Säulen-Struktur entstanden, ${ }^{166}$ deren Berechtigung aus heutiger Sicht nicht mehr plausibel ist. Zum anderen ermöglicht sie beständig bestehende horizontale Dekodifikationstenden-

158 Grundlegend A. Voßkuble, Strukturen und Bauformen neuer Verwaltungsverfahren, in: HoffmannRiem/Schmidt-Aßmann (Hrsg.), Verwaltungsverfahren (Fn. 8), S. 277 ff.; siehe auch Schmidt-Aßmann, Verfahrensgedanke (Fn. 146), \$27 Rn. 77-81; H. C. Röhl, Ausgewählte Verwaltungsverfahren, ebd., $\mathbb{S} 30$ Rn. 10-47; Schneider, Strukturen und Typen (Fn. 135), $\$ 28$ Rn. 158-173. Zum Verfahrenstyp „Verteilungsverfahren“ eingehend F. Wollenschläger, Verteilungsverfahren, Tübingen 2010, insb. S. 1-6, 11-13, 536-600, 630-633, 662-665.

159 Voßkuble, Verwaltungsverfahren (Fn.158), S. 347; Röhl, Ausgewählte Verwaltungsverfahren (Fn. 158), $\$ 30$ Rn. 9.

160 Näher unten F. V. 1.

161 Hierzu L. Prell, Verwaltungszusammenarbeit im Binnenmarkt, in: Burgi/Schönenbroicher (Hrsg.), Zukunft (Fn. 137), S. $48 \mathrm{ff}$.

162 Dargestellt bei Kahl, Entwicklung (Fn. 50), S. 121-126.

163 Eingehend und mit konkreten Vorschlägen Kahl, Europäisierung (Fn. 4), S. 55-91.

164 Siehe oben D. I. 1. b) bei und mit Fn. 50.

165 Vgl. unten F. IV.

166 Siehe oben E. I. 
zen. Seit Inkrafttreten des VwVfG wurde zum einen - entgegen guter Absichten ${ }^{167}$ - Sonderverfahrensrecht aus der Zeit vor dem VwVfG nicht abgebaut. ${ }^{168}$ Zum anderen wurden stetig neue verfahrensrechtliche Regelungen außerhalb des VwVfG geschaffen, ${ }^{169}$ darunter rechtsgebietsübergreifend bedeutsame wie im Gesetz über die Umweltverträglichkeitsprüfung (UVPG). ${ }^{170}$ Verwaltungsverfahrensrechtliche Dekodifikation kann dabei grundsätzlich in zwei Richtungen verlaufen. In eine zwar dekodifizierende, dafür ihrerseits relativ stabile, da selbst kodifikatorischen Ansprüchen genügende Gesetzgebung. Ein Beispiel hierfür wäre das UGB I gewesen, das, wenn es beschlossen worden wäre, eine vierte Säule neben VwVfG, SGB X und AO gebildet hätte. ${ }^{171}$ Die andere Richtung führt hingegen auf den Weg zu völliger Rechtszersplitterung. Exemplarisch lässt sich das öffentlich-rechtliche Informationsrecht anführen. Angestoßen durch europäische Vorgaben und internationale Entwicklungen werden hier den Bürgern gegenüber dem Staat sowie mit öffentlichen, respektive öffentlich-rechtlichen ${ }^{172}$ Aufgaben betrauten Privaten nunmehr verfahrensunabhängige und materiell voraussetzungslose Ansprüche auf Zugang zu Informationen gewährt. Das Informationsfreiheitsgesetz (IFG) des Bundes und die es ergänzenden landesrechtlichen Gesetze ${ }^{173}$ enthalten allgemeine Informationszugangsansprüche, können aber von spezielleren Regelungen verdrängt werden (vgl. $\$ 1$ Abs. 3 IFG), was für Umweltinformationen durch das Umweltinformationsgesetz (UIG) des Bundes und seine landesrechtlichen Pendants, ${ }^{174}$ für Verbraucherinformationen durch das Verbraucherinformationsgesetz (VIG) des Bundes, für Archivgut des Bundes durch das Bundesarchivgesetz (BArchG) und für Stasi-Unterlagen durch das Stasi-Unterlagen-Gesetz (StUG) geschehen ist. ${ }^{175}$ An alle diese Regelungen

167 BT-Drs. 7/910, S. 30, 99, 108; BT-Drs. 7/4494, S. 13.

168 Henneke/Ruffert (Fn. 96), Vor $\$ 1$ Rn. 48; Bonk, 25 Jahre (Fn. 94), S. 637. Diese Feststellung impliziert freilich nicht, dass jegliches Sonderverfahrensrecht abzuschaffen wäre. Besondere Regelungsbedürfnisse können vielmehr besonderes Verfahrensrecht erfordern; vgl. auch J. Ziekow, Allgemeines und bereichsspezifisches Verwaltungsverfahrensrecht, in: M.-E. Geis/D. C. Umbach (Hrsg.), Planung - Steuerung - Kontrolle. Festschrift für Richard Bartlsperger zum 70. Geburtstag, Berlin 2006, S. 247 (253-259).

169 Kahl, Kodifikationsidee (Fn. 8), S. 72-79; M. Burgi, Verwaltungsverfahrensrecht zwischen europäischem Umsetzungsdruck und nationalem Gestaltungsunwillen, JZ 2010, S. 105 (109).

170 Henneke/Ruffert (Fn. 96), Vor $\$ 1$ Rn. 46. In Bayern wurden demgegenüber Vorschriften über die Umweltverträglichkeitsprüfung in das BayVwVfG integriert (Art. 78 aff.).

171 Deswegen kritisch Burgi, Verwaltungsverfahrensrecht (Fn.169), S. 109 f.; K. Schönenbroicher, VwVfG, AO, SGB X und UGB? Wie viele „Säulen“ braucht das Verwaltungsverfahrensrecht?, in: Hill et al. (Hrsg.), 35 Jahre (Fn. 34), S. 263 (268); H. J. Bonk/H. Schmitz, in: Stelkens/Bonk/Sachs (Hrsg.), Verwaltungsverfahrensgesetz, (Fn. 93), $\$ 2$ Rn. 2 f.

172 Dass die Gesetzestexte insoweit teilweise unterschiedlich formuliert sind (vgl. z.B. \$1 Abs. 1 S. 3 IFG einerseits, $\mathbb{} 2$ Abs. 1 Nr. 2 UIG andererseits) begründet keinen Unterschied in der Sache; vgl. $F$. Schoch, Informationsfreiheitsgesetz, München 2009, $\$ 1$ Rn. 114-116.

173 Überblick bei Schoch (Fn. 172), Einleitung Rn. 102-117.

$174 \mathrm{Zu}$ ihnen T. Schomerus/U. Tolkmitt, Die Umweltinformationsgesetze der Länder im Vergleich, NVwZ 2007, S. $1119 \mathrm{ff}$.

175 Siehe Schoch (Fn. 172), $\$ 1$ Rn. 171-178. 
schließt das Informationsweiterverwendungsgesetz (IWG) an. ${ }^{176}$ Das Datenschutzrecht ist im Bundesdatenschutzgesetz (BDSG) und in den Landesdatenschutzgesetzen ${ }^{177}$ ebenfalls gesondert geregelt. Dieser Zustand einer heillosen Rechtszersplitterung ist vor allem aus Gründen rechtsstaatlicher Orientierungssicherheit und Transparenz inakzeptabel und ruft das dringende Bedürfnis nach Rekodifikation in das VwVfG hervor. ${ }^{178}$

\section{Simultangesetzgebung}

Eine Besonderheit des VwVfG als Kodifikation ist, dass es die durch es angestrebte Rechtsvereinheitlichung nicht allein herbeiführen kann. Die grundgesetzliche Verteilung der Gesetzgebungskompetenzen verwehrt es dem Bundesgesetzgeber, neben dem Verwaltungsverfahrensrecht betreffend die Verwaltungstätigkeit der Bundesbehörden auch das Verwaltungsverfahrensrecht betreffend die Verwaltungstätigkeit der Landesbehörden vollumfänglich zu regeln. ${ }^{179}$ Deshalb haben sich Bund und Länder im Vermittlungsausschuss auf die Regelung des $\$ 1$ Abs. 3 VwVfG geeinigt, der bestimmt, dass für die Ausführung von Bundesrecht durch die Länder das VwVfG nicht gilt, wenn ein Landesverwaltungsverfahrensgesetz Platz greift. ${ }^{180} \mathrm{Um}$ gleichwohl ein bundesweit weitgehend einheitliches Verwaltungsverfahrensrecht zu ermöglichen, beschloss die Ständige Konferenz der Innenminister der Länder am 20. 02. 1976, nach Erlass des VwVfG auf inhaltsgleiche Landesverwaltungsverfahrensgesetze hinzuwirken. ${ }^{181}$ Diese Praxis wird seitdem beibehalten, so dass das VwVfG und die Landesverwaltungsverfahrensgesetze weitgehend einheitlich sind. Die Länder erlassen entweder wortgleiche Vorschriften oder verweisen dynamisch auf das VwVfG. ${ }^{182}$ Eine Änderung des VwVfG ist deshalb de facto nur im Wege der Simultangesetzgebung, ${ }^{183}$ d.h. einem koordinierten legislativen Vorgehen unterschiedlicher Gesetzgeber, möglich. Für das VwVfG hat sich für diese Gesetzgebung im Konvoi ein von außen schwer durchschaubarer Abstimmungsprozess auf vor-

176 Hierzu O. Püschel, in: J. Fluck/A. Theuer (Hrsg.), Informationsfreiheitsrecht, Bd. 1, Heidelberg u.a., Loseblatt (Stand: 2012), IWG, Einführung Rn. 70-100.

$177 \mathrm{Zu}$ diesen W. Däubler/T. Klebe/P. Wedde/T. Weichert, Bundesdatenschutzgesetz, 3. Aufl., Frankfurt a. M. 2010, Einleitung Rn. 69 f.; W. Durner, Zur Einführung: Datenschutzrecht, JuS 2006, S. 213 (214).

178 Siehe unten F. V. 5.

179 H. Maurer, Allgemeines Verwaltungsrecht, 18. Aufl., München 2011, 55 Rn. 4; Bonk/Schmitz (Fn. 171), $\mathbb{1} 1 \mathrm{Rn} .32-38$. Zur damit verbundenen Problematik für den allgemeinen Verfahrensbegriff siehe Schmidt-Aßmann, Verfahrensgedanke (Fn. 146), $\$ 27$ Rn. 9-11.

180 Sachs (Fn. 93), Einleitung Rn. 36.

181 Ule, Kodifizierung (Fn. 135), S.1176f.; Abdruck des Beschlusses bei P. Stelkens/M. Sachs, in: P. Stelkens/H. J. Bonk/M. Sachs (Hrsg.), Verwaltungsverfahrensgesetz, 6. Aufl., München 2001, Einleitung Rn. 60.

182 U. Schliesky, in: Knack/Henneke (Hrsg.), Verwaltungsverfahrensgesetz (Fn. 96), $\$ 1$ Rn. 59-64; Kopp/Ramsauer (Fn. 90), Einführung I Rn. 7-9.

183 Begriffsprägend Klappstein, Rechtseinheit (Fn. 95), S. 7; ders., Möglichkeiten und Grenzen einer Simultangesetzgebung, ZG 1997, S. $126 \mathrm{ff}$. 
nehmlich ministerieller Ebene eingespielt, ${ }^{184}$ dem bisweilen - nicht ganz zu Unrecht - Abschottungstendenzen und Verantwortlichkeitsverwischung vorgeworfen werden. ${ }^{185}$

Die Simultangesetzgebung ist eine Strategie, die mit einer Kodifikation verbundene Rechtsvereinheitlichung über Kompetenzgrenzen hinweg sicherzustellen. Sie hat den Preis, dass inhaltliche Änderungen des VwVfG stets auf das konsensfähige Minimum beschränkt bleiben. ${ }^{186}$ Zwar würde sich das Verwaltungsverfahrensrecht von seiner kompetenziellen Ausgangssituation her dazu eignen, im Wege wettbewerbsföderalistischer Mechanismen innovative Lösungen zu entwickeln, ${ }^{187}$ indem einzelne Länder aus dem Konvoi ausscheren und eigene Vorschriften in „ihrem“ Verwaltungsverfahrensgesetz „ausprobieren“. Hiermit wäre zwar eine vertikale Dekodifikation verbunden, ${ }^{188}$ doch könnte nach der Bewährung neuer Lösungen ein Rekodifikationsprozess im Bund und den anderen Ländern einsetzen. ${ }^{189}$ Von Seiten der Beteiligten wird allerdings mit dem Argument der Rechtseinheit die Weiterführung der derzeitigen Praxis empfohlen. ${ }^{190}$

\section{Reformbestrebungen}

Auf Grundlage der Erfahrungen mit dem VwVfG im Rechtsalltag und des wissenschaftlichen „Abklopfens“ des Gesetzes auf seine Leistungsfähigkeit zur Bewältigung der an ein modernes Verwaltungsrecht gerichteten Erwartungen werden immer wieder Reformvorschläge für das VwVfG formuliert. ${ }^{191}$ Immer wieder erhobene Forderungen sind etwa die Regelung des sog. inneren Verwaltungsverfahrens, ${ }^{192}$ die

184 Vgl. H. Schmitz, Simultangesetzgebung von Bund und Ländern im Verwaltungsverfahrensrecht: Notwendigkeit und Umsetzungsmechanismen, in: Hill et al. (Hrsg.), 35 Jahre (Fn. 34), S. 253 (255-257); Klappstein, Simultangesetzgebung (Fn. 183), S. 127.

185 Burgi, Verwaltungsverfahrensrecht (Fn. 169), S. 111.

186 Wahl, Genehmigungsverfahren (Fn.143), S.1194; Klappstein, Simultangesetzgebung (Fn. 183), S. 128. Einen Vorteil sieht hierhin hingegen Schmitz, Simultangesetzgebung (Fn. 184), S. 257 f., der für ein behutsames Vorgehen bei Änderungen des VwVfG plädiert.

187 Dafür Burgi, Verwaltungsverfahrensrecht (Fn. 169), S. 111; Schönenbroicher, „Säulen“ (Fn. 171), S. $267 \mathrm{f}$.

188 Entgegen Burgi, Verwaltungsverfahrensrecht (Fn. 169), S. 111, kann die Bezeichnung „Dekodifikation“ im Bundesstaat auch über die vertikalen Regelungsebenen hinweg verwendet werden. Wie oben (D. I. 2.) gesehen, sind vertikale Regelungsebenen überspannende Kodifikationen nicht ausgeschlossen, sondern es kommt auf die Kompetenz zum Erlass derartiger Regelungen an. Dasselbe gilt freilich auch umgekehrt. Wenn ein Land bundesweit einheitliche Regelungen für den Geltungsbereich seiner Gesetze ändert (was es nur kann, wenn es die Kompetenz hierzu hat), liegt eine Dekodifikation vor. Aufgrund des Wechselspiels von De- und Rekodifikation muss diese aber nicht a priori nachteilig sein.

189 Zum Wechselspiel von De- und Rekodifikation siehe oben D. I. 1. c).

190 Vgl. Beirat Verwaltungsverfahrensrecht beim Bundesministerium des Innern, „Bewährtes Weiterentwickeln“. Empfehlung des Beirats Verwaltungsverfahrensrecht beim Bundesministerium des Innern zum Novellierungsbedarf der Verwaltungsverfahrensgesetze, NVwZ 2010, S. 1078 (1079).

191 Übersicht und Nachweise bei Stelkens, Kodifikationssinn (Fn. 34), S. 278 f.; jüngst S. Eisenmenger, Moderne Verwaltung - Modernes Verfahren, GewArch 2012, S. 145 ff., $192 \mathrm{ff}$.

192 Vgl. Hoffmann-Riem, Verwaltungsverfahren (Fn. 34), S. 40 f. 
Schaffung von Modellregelungen zum Erlass abstrakt-genereller Regelungen durch die Verwaltung, insbesondere in Form von Rechtsverordnungen und Verwaltungsvorschriften, ${ }^{193}$ oder die Forderung nach der Überführung der Regelungen des VwVG und des VwZG in das VwVfG. ${ }^{194}$ Hinzu kommen seit geraumer Zeit vor allem die Forderungen nach einer adäquaten rechtsförmigen Einhegung der Europäisierung und Internationalisierung des Verwaltungsverfahrensrechts, ${ }^{195}$ der Reaktion auf technische Entwicklungen (Stichwort: E-Government) ${ }^{196}$ und der Aufnahme von Regelungen betreffend die Mediation. ${ }^{197}$ Im Folgenden gilt es, für die Entwicklung des nationalen Verwaltungsverfahrensrechts bedeutsame und aktuelle Reformthemen näher vorzustellen, zumal für einige von ihnen konkrete Regelungsvorschläge vorgelegt wurden.

\section{Eröffnungskontrollen und (förmliche) Genehmigungsverfahren}

Seit geraumer Zeit wird vorgeschlagen, Stamm- bzw. Modellregelungen zu unterschiedlichen Eröffnungskontrollen und zu förmlichen Genehmigungsverfahren in das VwVfG aufzunehmen. ${ }^{198}$ Derartige Regelungen würden es erlauben, die unterschiedlichen de lege lata bestehenden sowie de lege ferenda zu schaffende Eröffnungskontrollen typisierend zu erfassen, soweit nötig ihre Rechts-, d.h. vor allem Konzentrationswirkungen, zu regeln und die einzelnen Eröffnungskontrollen für sie

193 Siehe Fn. 148. Das Landesverwaltungsgesetz Schleswig-Holstein (LVwG S-H) kennt solche Vorschriften: $\mathbb{S} 53 \mathrm{ff}$. LVwG S-H.

194 W. Schmitt Glaeser, Anspruch, Hoffnung und Erfüllung. Das Verwaltungsverfahren und sein Gesetz - eine einleitende Bemerkung, in: ders. (Hrsg.), Verwaltungsverfahren. Festschrift zum 50-jährigen Bestehen des Richard Boorberg Verlags, Stuttgart u.a. 1977, S. 1 (6 f.); Stelkens, Kodifikationssinn (Fn. 34), S. 287. In Schleswig-Holstein ( $\$ \mathbb{S} 146$ ff., 228 ff. LVwG S-H) und Mecklenburg-Vorpommern ( $\$ \int 94 \mathrm{ff}$. LVwVfG) sind die Zustellungs- und Vollstreckungsregeln bereits integriert.

195 Siehe oben Fn. 4.

196 Hierzu K. Ruge, Das VwVfG vor neuen Herausforderungen - Informations- und Kommunikationstechniken, in: Hill et al. (Hrsg.), 35 Jahre (Fn. 34), S. 299 ff., insb. S. 306-312; G. Britz, Reaktionen des Verwaltungsverfahrensrechts auf die informationstechnischen Vernetzungen der Verwaltung, in: Hoffmann-Riem/Schmidt-Aßmann (Hrsg.), Verwaltungsverfahren (Fn. 8), S. 213 ff. Aus der Praxis wird hier vor allem Rechtssicherheit in Hinblick auf die Gerichtsfestigkeit von elektronischen Akten angemahnt; siehe A. Metschke, Wahrnehmung und Bedeutung des Verwaltungsverfahrensrechts aus der Sicht des Anwenders: Verwaltung, in: Hill et al. (Hrsg.), 35 Jahre (Fn. 34), S. 56 (64 f.).

197 H. Schulze-Fielitz, Der Konfliktmittler als verwaltungsverfahrensrechtliches Problem, in: W. Hoffmann-Riem/E. Schmidt-Aßmann (Hrsg.), Konfliktbewältigung durch Verhandlungen, Bd. II, BadenBaden 1990, S. 55 (64-66); Beschlüsse Nr. 19 f. der Abteilung Mediation des 67. Deutschen Juristentages, in: Ständige Deputation des Deutschen Juristentages (Hrsg.), Verhandlungen des 67. Deutschen Juristentages, Bd. II/1, München 2008, S. O 79; R. Pitschas, Mediation als kollaborative Governance, DÖV 2011, S. 333 (339); Ziekow, Governance (Fn. 141), S. 107. Das nunmehr in Kraft getretene Gesetz zur Förderung der Mediation und anderer Verfahren der außergerichtlichen Konfliktbeilegung vom 21.7.2012, BGBl. I, S. 1577 ff., ändert das VwVfG nicht. Die allgemeinen Regelungen betreffend die Mediation gelten zwar auch für die vorgerichtliche Mediation und in Verwaltungsverfahren ist Mediation nicht ausgeschlossen; dass sie sich hier unter der geltenden Rechtslage großflächig etabliert ist allerdings unwahrscheinlich. Zum Ganzen J. M. von Bargen, Mediation im Verwaltungsverfahren nach Inkrafttreten des Mediationsförderungsgesetzes, ZUR 2012, S. 468 ff.; M. Eisenbarth/I. Spiecker genannt Döhmann, Der Verwaltungsprozess und das erste deutsche Mediationsgesetz Streit über den Weg der Streitentscheidung, DVBl. 2012, S. $993 \mathrm{ff}$.

198 Grundlegend Wahl, Genehmigungsverfahren (Fn. 143), S. $1192 \mathrm{ff}$. 
adäquaten Verfahrenstypen zuzuordnen. ${ }^{199}$ Da das VwVfG außer dem Planfeststellungsbeschluss und der Plangenehmigung $(\mathbb{S} 74)$ sowie der Genehmigungsfiktion

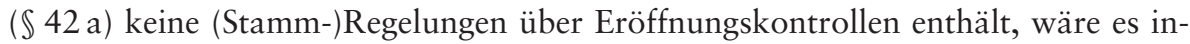
sofern zu ergänzen. In Rede stehen vor allem die (anlagen- wie personenbezogene $)^{200}$ Genehmigung sowie die Anzeige, bei der wiederum unterschieden werden kann, ob sie allein dazu dient, die Behörde zu informieren, damit sie gegebenenfalls repressiv tätig werden kann oder ob sie auch die Funktion hat, eine eventuell bestehende Genehmigungsbedürftigkeit durch die Behörde klären zu lassen. ${ }^{201}$ Auch der neu zu schaffende Genehmigungstyp der integrierten Vorhabengenehmigung, der im UGB I vorgesehen war, hätte hier seinen Regelungsplatz. ${ }^{202}$ Hinsichtlich der zu normierenden Verfahrenstypen wurde überzeugend vorgeschlagen, zusätzlich zu den bestehenden Vorschriften über das Planfeststellungsverfahren ( $\mathbb{S} 72 \mathrm{ff}$. VwVfG) Stammregelungen für ein Genehmigungsverfahren mit und ein Genehmigungsverfahren ohne Öffentlichkeitsbeteiligung sowie ein Anzeigeverfahren in das VwVfG aufzunehmen. ${ }^{203}$ Die Kodifikationsfähigkeit und Kodifikationsbedürftigkeit dieses Regelungsfeldes haben Martin Burgi und Wolfgang Durner überzeugend herausgearbeitet und als Diskussionsgrundlage für eine derartige Reform konkrete Formulierungsvorschläge unterbreitet. ${ }^{204}$ Die Aufnahme von Stammregelungen zu Eröffnungskontrollen und Genehmigungsverfahren ist in der Tat sinnvoll und wünschenswert. Eine dahingehende Reform des VwVfG erscheint derzeit gleichwohl fraglich, ${ }^{205}$ zumal auch sie sich - wie bereits das Projekt UGB - aller Wahrscheinlichkeit nach aus Ressortegoismen erwachsendem Widerstand ausgesetzt sehen wird. ${ }^{206}$

\section{Verfahrensfehlerfolgen}

Während dem Verwaltungsverfahren früher eine rein dienende bzw. - nach neuerer, präziserer Terminologie - instrumentelle Funktion zugesprochen wurde, ${ }^{207}$ hat sich mittlerweile, nicht zuletzt aufgrund unionsrechtlicher und internationaler Einflüs-

199 Burgi, Verwaltungsverfahrensrecht (Fn. 169), S. 110.

200 Zur geringen Bedeutung dieser Unterscheidung für eine Kodifizierung von Stammregelungen für Genehmigungen siehe Burgi/Durner, Modernisierung (Fn. 140), S. 52-55, 88 (dort $\$ 71 \mathrm{n}$ Abs. 3).

201 M. Burgi, Das VwVfG und der Kodifikationsgedanke: Reform der Eröffnungskontrollen und des förmlichen Verfahrens I, in: Hill et al. (Hrsg.), 35 Jahre (Fn. 34), S. 215 (224).

202 Kahl/Welke, Vorhabengenehmigung (Fn. 120), S. 1414 ff., insb. S. 1422 f.

203 W. Durner, Reform der Eröffnungskontrollen und des förmlichen Verfahrens II: die Normierung eines allgemeinen Genehmigungsverfahrens im Verwaltungsverfahrensgesetz, in: Hill et al. (Hrsg.), 35 Jahre (Fn. 34), S. 237 (246); zu Anzeigeverfahren siehe auch, wenngleich zurückhaltender, $H$. Schmitz, Moderner Staat - Modernes Verwaltungsverfahrensrecht, NVwZ 2000, S. 1238 (1239 f.).

204 Burgi/Durner, Modernisierung (Fn. 140), S. 49-129, Vorschläge auf S. 87-89, 122.

205 Siehe die zurückhaltenden Töne beim Beirat Verwaltungsverfahrensrecht beim Bundesministerium des Innern, „Bewährtes Weiterentwickeln“ (Fn. 190), S. 1079.

206 Wahl, Genehmigungsverfahren (Fn. 143), S. 1195.

207 Zu Terminologie und Sache M. Fehling, Eigenwert des Verfahrens im Verwaltungsrecht, VVDStRL 70 (2011), S. 278 (281-288). 
se, ${ }^{208}$ die Auffassung durchgesetzt, dass dem Verfahren auch weitere Zwecke bis hin zum Selbstzweckcharakter zukommen können. ${ }^{209}$ Vor diesem Hintergrund plädiert vor allem Martin Burgi dafür, in das VwVfG eine Zweckbestimmungsklausel aufzunehmen, die zwar den instrumentellen Charakter des Verfahrens als „Verwirklichungsmodus des Verwaltungsrechts" 210 statuiert, aber gleichzeitig normiert, dass Vorschriften über das Verwaltungsverfahren weitere Zwecke des Verfahrens bestimmen können. In Kombination hiermit sollen die viel kritisierten Verfahrensfehlerfolgevorschriften der $\mathbb{S} \mathbb{4} 45 \mathrm{Abs.} 2,46 \mathrm{VwVfG}$ dahingehend ergänzt werden, dass sie nicht für Verfahrensvorschriften, die weitere Zwecke bestimmen, gelten sollen. ${ }^{211}$ Bei der Verletzung einer derartigen Verfahrensvorschrift wäre dann weder Heilung möglich noch ein infolge der Verletzung bestehender Aufhebungsanspruch ausgeschlossen. Eine entsprechende Anpassung der $\mathbb{S} 45$ Abs. 2, 46 VwVfG wäre zu begrüßen. Ob es dafür indes einer Verfahrenszweckbestimmungsklausel im VwVfG bedarf erscheint fraglich. Sofern man dies anders sieht, sollte aber zumindest die vorgeschlagene Formulierung, ${ }^{212}$ die auch ermöglichen will, dass Verfahrensvorschriften implizit weitere Zwecke „bestimmen“ können, ${ }^{213}$ dahingehend umformuliert werden, dass Vorschriften über das Verwaltungsverfahren weiteren Zwecken dienen können.

\section{Bürgerbeteiligung bei Großvorhaben}

Keineswegs neu ist die Debatte um eine angemessene Bürgerbeteiligung bei Großvorhaben, ${ }^{214}$ die durch die sich in den Jahren 2010 und 2011 verdichtenden Ereignisse bezüglich des Bahnhofsumbauprojekts „Stuttgart 21“ erneut angeschoben wurde. $^{215}$ Hierbei wurden auch Forderungen nach einer Anpassung des Verwal-

208 Vgl. W. Kahl, Grundrechtsschutz durch Verfahren in Deutschland und in der EU, VerwArch 95 (2004), S. 1 ff.; J. Ziekow, Von der Reanimation des Verfahrensrechts, NVwZ 2005, S. 263 ff.

209 Eingehend E. Gurlit und M. Fehling, Eigenwert des Verfahrens im Verwaltungsrecht, VVDStRL 70 (2011), S. 227 ff. bzw. S. $278 \mathrm{ff}$.

210 R. Wahl, Verwaltungsverfahren zwischen Verwaltungseffizienz und Rechtsschutzauftrag, VVDStRL 41 (1983), S. 151 (153).

211 Burgi, Verwaltungsverfahrensrecht (Fn. 169), S. 108 f.; ders., Die dienende Funktion des Verwaltungsverfahrens: Zweckbestimmung und Fehlerfolgenrecht in der Reform, DVBl. 2011, S. 1317 ff.; ders., Eröffnungskontrollen (Fn. 201), S. 226-235; ders./Durner, Modernisierung (Fn. 140), S. 24-48.

212 „Das Verwaltungsverfahren dient dem Erlass eines recht- und zweckmäßigen Verwaltungsaktes oder dem Abschluss eines recht- und zweckmäßigen öffentlich-rechtlichen Vertrages. Vorschriften über das Verwaltungsverfahren können weitere Zwecke bestimmen. “

213 Vgl. Burgi/Durner, Modernisierung (Fn. 140), S. 46 f.

214 Siehe nur W. Blümel (Hrsg.), Frühzeitige Bürgerbeteiligung bei Planungen, Berlin 1982.

215 Zum Ablauf des Projekts „Stuttgart 21“ T. Groß, Stuttgart 21 - Folgerungen für Demokratie und Verwaltungsverfahren, in: Hill et al. (Hrsg.), 35 Jahre (Fn. 34), S. 31 (31-33). Ausgewogen kritisch zu den in diesem Zusammenhang ausgemachten angeblichen Krisensymptomen K. F. Gärditz, Angemessene Öffentlichkeitsbeteiligung bei Infrastrukturplanungen als Herausforderung an das Verwaltungsrecht im demokratischen Rechtsstaat, GewArch 2011, S. 273 (276f.). 
tungsverfahrensrechts laut. ${ }^{216}$ Von der Politik aufgegriffen wurde der Vorschlag einer frühen Bürgerbeteiligung im Planfeststellungsverfahren. ${ }^{217}$ Unter Betonung des Kodifikationsgedankens hat der Beirat Verwaltungsverfahrensrecht beim Bundesministerium des Innern empfohlen, eine Regelung über die frühzeitige Bürgerbeteiligung für alle Genehmigungsverfahren, die raumbedeutsame Vorhaben mit Auswirkungen auf eine größere Zahl von Betroffenen zum Gegenstand haben, in die Allgemeinen Vorschriften über das Verwaltungsverfahren (Teil II. des VwVfG) aufzunehmen. ${ }^{218}$ Sie soll keine Verpflichtung, sondern eine Obliegenheit des Vorhabenträgers statuieren, noch vor Beginn des Genehmigungsverfahrens die Öffentlichkeit zu beteiligen; die Behörden sollen verpflichtet werden, hierauf hinzuwirken. Ein entsprechender Gesetzesentwurf zur Einfügung eines neuen Abs. 3 in $\$ 25 \mathrm{VwVfG} \mathrm{liegt}$ bereits vor. ${ }^{219}$ Die ausdrückliche Normierung im VwVfG für alle Genehmigungsverfahren wäre begrüßenswert. ${ }^{220}$ Zwar hatten die Vorhabenträger auch bisher schon die Möglichkeit, die Öffentlichkeit vor Beginn des Genehmigungsverfahrens zu beteiligen; die Behörden konnten dies auch anregen. ${ }^{221}$ Von der ausdrücklichen Normierung dieser Möglichkeit kann aber eine Anstoßwirkung ausgehen. Die Ausweitung der Regelung auf alle Genehmigungsverfahren ist sachgerecht, ${ }^{222}$ denn die Beteiligungsfragen stellen sich nicht nur bei Planfeststellungsverfahren. Richtig ist auch, dass die Durchführung der frühzeitigen Öffentlichkeitsbeteiligung nicht ver-

216 Überblick bei Burgi/Durner, Modernisierung (Fn. 140), S. 146-148. Zahlreiche weitere Vorschläge jetzt bei J. Ziekow, Neue Formen der Bürgerbeteiligung? Planung und Zulassung von Projekten in der parlamentarischen Demokratie. Gutachten D zum 69. Deutschen Juristentag, in: Ständige Deputation des Deutschen Juristentages (Hrsg.), Verhandlungen des 69. Deutschen Juristentages, Bd. I, München 2012, S. D 76-D 140, Zusammenfassung auf S. D 141-D 157.

217 Vgl. BR-Drs. 135/11. Dies aufgreifend und ebenfalls nur auf die Planfeststellung bezogen der Vorschlag von B. Stüer/D. Buchsteiner, Stuttgart 21: Eine Lehre für die Planfeststellung?, UPR 2011, S. 335 (340 f.).

218 Beirat Verwaltungsverfahrensrecht beim Bundesministerium des Innern, Für mehr Transparenz und Akzeptanz - frühere Öffentlichkeitsbeteiligung bei Genehmigungsverfahren, NVwZ 2011, S. $859 \mathrm{f}$.

219 BT-Drs. 17/9666, S. 7, 15, 16-18; siehe hierzu H.-G. Henneke, Wutbürger in Verantwortung: Partizipation und direkte Demokratie in Kommunen und Ländern, DVBl. 2012, S. 1072 (1073-1075); G. Winter, Reform des Verwaltungsverfahrens nach „Stuttgart 21“?, ZUR 2012, S. 329 f.; kritisch W. Hertel/C.-D. Munding, NJW 2012, S. 2622 ff.; Änderungsvorschlag in BR-Drs. 171/2/12 (neu), S. 1. Allerdings sind auch insoweit schon vorgreifende Dekodifikationstendenzen auszumachen; vgl. etwa die frühzeitige Einbeziehung der Öffentlichkeit im Rahmen der Antragskonferenz gem. $\mathbb{S} 57$ Abs. 2 S. 3, 20 Abs. 2 S. 3 Netzausbaubeschleunigungsgesetz (NABEG); hierzu BT-Drs. 17/6073, S. 25, 28; E. Hofmann, Die Modernisierung des Planungsrechts: das Energierecht als neues Paradigma der Öffentlichkeitsbeteiligung in einer Planungskaskade?, JZ 2012, S. 701 (707); vgl. zudem K. F. Gärditz, Die Entwicklung des Umweltrechts im Jahr 2011: Umweltpolitische Herausforderungen zwischen Partizipation, Wutbürgertum und Energiewende, ZfU 2012, S. 249 (271 f.), wenngleich mit Blick auf die Öffentlichkeitsbeteiligung gem. $\$ 9$ NABEG.

220 Einen Weg außerhalb des VwVfG schlägt hingegen M. Burgi, Das Bedarfserörterungsverfahren: Eine Reformoption für die Bürgerbeteiligung bei Großprojekten, NVwZ 2012, S. 277 ff., vor, indem er für die Normierung von Bedarfserörterungsverfahren in den Fachgesetzen plädiert; zustimmend und weitergehend Hofmann, Energierecht (Fn. 219), S. 704.

221 Stüer/Buchsteiner, Stuttgart 21 (Fn. 217), S. 341, dort auch Vorschläge zur Ausgestaltung der frühzeitigen Öffentlichkeitsbeteiligung; Ziekow, Bürgerbeteiligung (Fn. 216), S. D 87 f.

222 Für eine Beschränkung auf planfeststellungspflichtige sowie einer immissionsschutzrechtlichen Genehmigungspflicht unterliegende Vorhaben aber BR-Drs. 171/1/12, S. 1-3. 
pflichtend eingeführt werden soll. ${ }^{223}$ Deshalb ist auch der Vorschlag, eine Regelung einzuführen, die bestimmt, dass vor Beginn eines Planfeststellungsverfahrens der Vorhabenträger eine frühe Öffentlichkeitsbeteiligung durchführen „soll“,224 abzulehnen. Die rechtliche Austarierung der (Verfahrens-)Interessen der Allgemeinheit, der Vorhabenträger und der Betroffenen hinsichtlich der Genehmigung von Großprojekten lohnt zwar jederzeit der Überprüfung und der Diskussion um Anpassungsbedarf. Dabei darf aber nicht unter dem Eindruck singulärer Ereignisse, und seien sie noch so heftig oder lautstark, eine sachliche Bestandsaufnahme übersprungen werden. Diese ergibt, dass rechtliche Verpflichtungen zur Beteiligung der Öffentlichkeit bei der Genehmigung von Großvorhaben bereits in weitem Umfang bestehen. ${ }^{225}$ Es scheint deshalb nicht zu wenig Möglichkeiten von Öffentlichkeitsbeteiligung zu geben, sondern in erster Linie ein Kommunikationsproblem innerhalb der bereits bereitstehenden Beteiligungsverfahren. ${ }^{226}$ Hier muss daher zuvörderst angesetzt werden. Die stärkere Nutzung des Internets sowie entsprechende Personalschulung sind nur die naheliegendsten Vorschläge. ${ }^{227}$ Flankierend kann über die Vorschläge nachgedacht werden, die Einwendungs- und Präklusionsfristen im Planfeststellungsverfahren ( $\mathbb{S} 73$ Abs. 4 S. 1 und $3 \mathrm{VwVfG}$ ) zu verlängern und die Vorschriften betreffend das Beteiligungsverfahren dahingehend aufzuwerten, dass die Justiziabilität von Verstößen gegen sie erweitert wird. ${ }^{228}$ Sinnvoll wäre zudem in jedem Fall die Aufhebung von Differenzierungen zwischen Beteiligungs- und Einwendungsrechten der „Öffentlichkeit“, der „betroffenen Öffentlichkeit“ (vgl. $\$ 2$ Abs. 6 UVPG) oder dem in seinen Belangen Betroffenen (vgl. $\$ 73$ Abs. 4 S. 1 VwVfG).229

\section{Rekodifikation des Planfeststellungsrechts}

Die soeben dargestellten Reformbestrebungen hinsichtlich der frühen Öffentlichkeitsbeteiligung bei Großvorhaben sind eingebettet in den von der Bundesregierung eingebrachten Entwurf eines Gesetzes zur Verbesserung der Öffentlichkeitsbeteiligung und Vereinheitlichung von Planfeststellungsverfahren (PIVereinhG). ${ }^{230}$ Dieses

223 Kritisch hingegen R. Klinger, Frühe Öffentlichkeitsbeteiligung in der Planfeststellung, ZUR 2012, S. $201 \mathrm{f}$.

224 BR-Drs. 171/2/12 (neu), S. 2.

225 Gärditz, Öffentlichkeitsbeteiligung (Fn. 215), S. 273-276; Burgi/Durner, Modernisierung (Fn. 140), S. 153-158, 176-178.

226 Burgi/Durner, Modernisierung (Fn. 140), S. 179-181; E. Gurlit, Neue Formen der Bürgerbeteiligung? - Planung und Zulassung von Projekten in der parlamentarischen Demokratie, JZ 2012, S. 833 (835 f., 839), konstatiert ein geringes Mobilisierungspotenzial.

227 Weiterführend Gurlit, Bürgerbeteiligung (Fn. 226), S. 839 f.

228 Burgi/Durner, Modernisierung (Fn. 140), S. 184 f. bzw. S. 181 f.

229 Burgi/Durner, Modernisierung (Fn. 140), S. 162 f.; differenzierend M. Knauff, Öffentlichkeitsbeteiligung im Verwaltungsverfahren, DÖV 2012, S. 1 (7); vgl. zum Problem auch im Überblick A. Guckelberger, Formen von Öffentlichkeit und Öffentlichkeitsbeteiligung im Umweltverwaltungsrecht, VerwArch 103 (2012), S. $31 \mathrm{ff}$.

230 BT-Drs. 17/9666; Änderungsvorschläge in BR-Drs. 171/1/12, insb. S. 4-17; Stellungnahme des Bundesrats in BR-Drs. 171/12 (Beschluss). 
Gesetzesvorhaben verfolgt auch eine Rekodifikation des Planfeststellungsrechts in das VwVfG. Die bewährten und verallgemeinerungsfähigen Regelungen zum Planfeststellungsverfahren, die durch das Infrastrukturplanungsbeschleunigungsgesetz $^{231}$ in einige Fachgesetze eingefügt wurden und die Vorschriften des VwVfG zum Planfeststellungsverfahren modifizieren oder ergänzen, sollen in das VwVfG integriert werden und fortan grundsätzlich für alle Planfeststellungsverfahren gelten. ${ }^{232}$ Die Fachgesetze würden hierdurch verschlankt und das VwVfG als Kodifikation gestärkt, wenngleich freilich nicht alle Regelungen übernommen werden und auch weiterhin bereichsspezifisches Sonderrecht bestehen bleiben soll, sofern es sich nicht um verallgemeinerungsfähige Regelungen handelt. ${ }^{233}$ Einen Schwerpunkt der geplanten Neuregelungen bildet die weitgehende verfahrensrechtliche Gleichstellung der durch staatliche Anerkennung mit Rechtsbehelfsbefugnis ausgestatteten Vereinigungen - d.h. (derzeit) vor allem Vereinigungen gem. $\$ 3$ Abs. 1 UmwRG und gem. $\$ 63$ Abs. 1 BNatSchG - mit den von dem geplanten Vorhaben Betroffenen. ${ }^{234}$ Dies soll auch für die Präklusion von Einwendungen gem. $\$ 73$ Abs. 4 S. 3 VwVfG gelten. ${ }^{235}$ Der Entwurf zielt insgesamt auf Verfahrensbeschleunigung. ${ }^{236}$ Unabhängig wie man sich inhaltlich hierzu positioniert, belegt das Gesetzesvorhaben jedenfalls, dass Kodifikationsgesetzgebung sich heute als Prozess der De- und Rekodifikation darstellt ${ }^{237}$ und die Kodifikation weiterhin Anziehungskraft auf das Sonderrecht ausübt. ${ }^{238}$

\section{Informationszugang}

Wie bereits erwähnt, ist das öffentlich-rechtliche Informationsrecht zersplittert. ${ }^{239}$ Auf Länderebene wurde jüngst für Nordrhein-Westfalen der Entwurf eines die öffentlich-rechtlichen Informationsansprüche vereinheitlichenden Allgemeinen Informationsgesetzes NRW vorgelegt. ${ }^{240}$ Aus Sicht der Verwaltungsverfahrensgesetze ist ein eigenständig normiertes Informationszugangsrecht - gleich ob zersplittert oder

231 Gesetz zur Beschleunigung von Planungsverfahren für Infrastrukturvorhaben vom 9.12.2006, BGBl. I, S. $2833 \mathrm{ff}$.

232 BT-Drs. 17/9666, S. 13.

233 Überblick, welche Vorschriften nicht und welche übernommen werden sollen, bei BT-Drs. 17/9666, S. $14 \mathrm{f}$.

234 BT-Drs. 17/9666, S. 7, 14, $18 \mathrm{f}$.

235 Siehe BT-Drs. 17/9666, S. 7.

236 Siehe zu diesem Ziel übergreifend E. Schmidt-Aßmann, Verwaltungsverfahren und Verwaltungskultur, NVwZ 2007, S. $40 \mathrm{ff}$.

237 Siehe oben D. I. 1. c).

238 Die Anziehungskraft der Kodifikation zeigt sich auch daran, dass der Gesetzentwurf vorsieht, die bisher in $\$ 59 \mathrm{VwGO}$ normierte Rechtsbehelfsbelehrungspflicht leicht erweitert in einen neuen $\$ 37$ Abs. $6 \mathrm{VwVfG}$ zu überführen, wo sie regelungssystematisch stimmiger aufgehoben ist; siehe BT-Drs. 17/9666, S. 7, 8, 18, 21.

239 Siehe oben F. III.

240 Beckmann/Sensburg/Warg, Informationsgesetz (Fn. 99), S. 111 ff. Der Vorschlag leidet allerdings daran, dass ihm eine $\mathbb{\$} 8$ IFG oder $\$ 9$ Abs. 1 S. 3 UIG vergleichbare Vorschrift (Beteiligung von der Informationsfreigabe betroffener Dritter vor der Entscheidung über den Informationszugang) fehlt. 
kodifiziert - Sonderrecht. Um die diesbezügliche Dekodifikation zurückzudrehen und das VwVfG als die zentrale Kodifikation des Allgemeinen Verwaltungsrechts zu stärken, sollten die derzeit bestehenden Informationszugangsrechte zwar gebündelt, aber in das VwVfG integriert werden; wobei der Informationszugangsanspruch freilich unabhängig von einem konkreten Verwaltungsverfahren respektive der Beteiligtenstellung in einem solchen zu gewähren wäre. ${ }^{241}$ Die aus Kompetenzgründen notwendige Beschränkung auf Informationsansprüche gegenüber Behörden des Bundes (bzw. ihnen gleichgestellten Subjekten) wäre dabei kein Nachteil, da eine dahingehende Änderung des VwVfG ohnehin nur im Wege der Simultangesetzgebung erfolgen sollte, so dass die Länder in ihre LVwVfGe entsprechende Regelungen aufnehmen würden. Der Abstimmungsbedarf zwischen Bund und Ländern in dieser vergleichsweise neuen, zugleich mit alten Grundsätzen brechenden Materie ist allerdings hoch, weshalb eine derartige Reform derzeit leider unwahrscheinlich ist. ${ }^{242}$ Bis zu ihrer Realisierung böte sich immerhin noch die verfahrensmäßige Eingliederung der unterschiedlichen Informationsansprüche in das Verfahren der Akteneinsicht gem. $\$ 29$ VwVfG an. ${ }^{243}$

\section{Verwaltungskooperationsrecht}

Mit der verstärkten wissenschaftlichen Zuwendung zur Aufgabenwahrnehmungsverteilung zwischen der öffentlichen Hand und Privaten wurde auch die Frage nach deren gesetzlicher Einhegung gestellt und hinsichtlich des Regelungsstandorts unter anderem eine Ergänzung des VwVfG erwogen. ${ }^{244} \mathrm{Im}$ Auftrag des Bundesministeriums des Innern wurden 2001 zwei Reformentwürfe zur Normierung eines Verwaltungskooperationsrechts, das einen Regelungsrahmen für Kooperationsbeziehungen zwischen Verwaltung und Privaten (Public Private Partnerships) entwerfen sollte, vorgelegt, die beide für eine Ergänzung des VwVfG um entsprechende Vorschriften

241 Wie hier für eine VwVfG-Lösung J. Masing, Transparente Verwaltung: Konturen eines Informationsverwaltungsrechts, VVDStRL 63 (2004), S. 377 (433-435 m. Fn. 167); R. Breuer, Zugang zu Informationen, in: H.-P. Mansel/B. Dauner-Lieb/M. Henssler (Hrsg.), Zugang zum Recht: Europäische und US-amerikanische Wege der privaten Rechtsdurchsetzung, Baden-Baden 2008, S. 29 (41, 54). Gegen eine Integration in das VwVfG und für eine eigenständige Kodifikation hingegen Schoch (Fn. 172), Einleitung Rn. 162; vgl. auch E. Schmidt-Aßmann, Verwaltungsverfahren, in: Isensee/ Kirchhof (Hrsg.), Handbuch (Fn. 39), $\$ 109$ Rn. 13. Für deren Ansicht spricht, dass die Existenz eines allgemeinen Informationszugangsanspruchs den Bürgern durch ein eigenes Gesetzeswerk mit griffigem Namen (der Titel „Informationsfreiheitsgesetz“ ist hier durchaus gut gewählt) besser vermittelt werden kann.

242 Vgl. auch H. Schmitz, Fortentwicklung des Verwaltungsverfahrensgesetzes: Konkrete Gesetzgebungspläne und weitere Perspektiven, in: Hoffmann-Riem/Schmidt-Aßmann (Hrsg.), Verwaltungsverfahren (Fn. 8), S. 135 (143).

243 Vorschlag hierzu bei Burgi/Durner, Modernisierung (Fn. 140), S. 134-136.

244 Vgl. A. Voßkuble, Beteiligung Privater an der Wahrnehmung öffentlicher Aufgaben und staatliche Verantwortung, VVDStRL 62 (2003), S. 266 (327), unter dem Begriff „Gewährleistungsverwaltungsrecht". 
plädierten. ${ }^{245}$ Der Beirat Verwaltungsverfahrensrecht beim Bundesministerium des Innern empfahl auf dieser Grundlage zwar „nur“ eine Reform der Regelungen über den öffentlich-rechtlichen Vertrag ( $\mathbb{S} 54 \mathrm{ff}$. VwVfG) unter Einschluss der Normierung eines „Kooperationsvertrags“. ${ }^{246}$ Immerhin wird dieses Reformvorhaben aber auch aktuell noch weiterverfolgt. ${ }^{247}$

\section{G. Schluss}

Die Kodifikationsidee ist im Verwaltungsrecht nicht obsolet. Sie muss aber differenziert gesehen werden. Dies bedeutet auch, sie vor idealistischen Überhöhungen sowie übersteigerten bzw. verzerrend dargestellten Anforderungen zu bewahren. Unter Beachtung der nötigen Differenzierungen bleiben Kodifikationen auch im Verwaltungsrecht und auch im 21. Jahrhundert möglich. Sowohl ihre Entstehung als auch ihr Bestand wird allerdings in den meisten Fällen von einem - nicht selten wechselvollen - Prozess der De- und Rekodifikation begleitet sein. Die beständigen Reformdiskussionen und vor allem die aktuellen Reformvorschläge und -vorhaben zeigen aber, dass sich der Einsatz von Wissenschaft und Praxis für eine kodifikatorische Gesetzgebung im Verwaltungsrecht weiterhin lohnt. Kodifikatorische Gesetzgebung sollte ihr Hauptaugenmerk dabei gerade auf die systembildende Bedeutung Allgemeiner Teile richten.

245 G. F. Schuppert, Grundzüge eines zu entwickelnden Verwaltungskooperationsrechts, 2001, insb. S. 124-133; J. Ziekow, Verankerung verwaltungsrechtlicher Kooperationsverhältnisse (Public Private Partnership) im Verwaltungsverfahrensgesetz, 2001, insb. S. 198-211; siehe auch H. Bauer, Verwaltungswissenschaftliche Impulse für die Fortentwicklung der Lehre vom Verwaltungsvertrag, in: W. Kluth/A. Peilert (Hrsg.), Wirtschaft, Verwaltung, Recht. Festschrift für Rolf Stober zum 65. Geburtstag am 11. Juni 2008, Köln, München 2008, S. 327 ff.; sowie zuletzt T. Gas, Die gesetzliche Normierung des öffentlich-privaten Kooperationsvertrages, Die Verwaltung 45 (2012), S. 43 ff., insb. S. 51-55, mit ausgearbeitetem Gesetzesvorschlag auf S. 65-79. Für eine Regelung außerhalb des VwVfG in einem Public-Private-Partnership (PPP)-Gesetz hingegen M. Burgi, Privatisierung öffentlicher Aufgaben - Gestaltungsmöglichkeiten, Grenzen, Regelungsbedarf. Gutachten D für den 67. Deutschen Juristentag, in: Ständige Deputation des Deutschen Juristentages (Hrsg.), Verhandlungen des 67. Deutschen Juristentages, Bd. I, München 2008, S. D 109-D 113; Beschluss Nr. 22 der Abteilung Öffentliches Recht des 67. Deutschen Juristentages, in: Ständige Deputation des Deutschen Juristentages (Hrsg.), Verhandlungen des 67. Deutschen Juristentages, Bd. II/1, München 2008, S. M 80.

246 Beirat Verwaltungsverfahrensrecht beim Bundesministerium des Innern, Fortentwicklung der Vorschriften über den öffentlich-rechtlichen Vertrag ( $\mathbb{S} 5$ 54-62 VwVfG), NVwZ 2002, S. 834 f. Erläuterungen und Abdruck eines Bund/Länder-Musterentwurfs bei H. Schmitz, „Die Verträge sollen sicherer werden “ - Zur Novellierung der Vorschriften über den öffentlich-rechtlichen Vertrag, DVBl. 2005, S. 17 ff. Kritisch Stelkens, Kodifikationssinn (Fn. 34), S. 280-284.

247 So Schmitz/Prell, Europäische Verwaltungszusammenarbeit (Fn. 50), S. 1127. 